\title{
Elevation of brain magnesium prevents synaptic loss and reverses cognitive deficits in Alzheimer's disease mouse model
}

\author{
Wei Li ${ }^{1}$, Jia Yu ${ }^{2}$, Yong Liu ${ }^{3}$, Xiaojie Huang ${ }^{1}$, Nashat Abumaria', Ying Zhu ${ }^{1}$, Xian Huang ${ }^{1}$, Wenxiang Xiong ${ }^{1}$, Chi Ren ${ }^{1}$,
} Xian-Guo Liü ${ }^{3}$ Dehua Chui ${ }^{2}$ and Guosong Liü*

\begin{abstract}
Background: Profound synapse loss is one of the major pathological hallmarks associated with Alzheimer's disease, which might underlie memory impairment. Our previous work demonstrates that magnesium ion is a critical factor in controlling synapse density/plasticity. Here, we tested whether elevation of brain magnesium, using a recently developed compound (magnesium-L-threonate, MgT), can ameliorate the AD-like pathologies and cognitive deficits in the APPswe/PS1dE9 mice, a transgenic mouse model of Alzheimer's disease.
\end{abstract}

Results: MgT treatment reduced A $\beta$-plaque, prevented synapse loss and memory decline in the transgenic mice. Strikingly, MgT treatment was effective even when the treatment was given to the mice at the end-stage of their Alzheimer's disease-like pathological progression. To explore how elevation of brain magnesium ameliorates the AD-like pathologies in the brain of transgenic mice, we studied molecules critical for APP metabolism and signaling pathways implicated in synaptic plasticity/density. In the transgenic mice, the NMDAR signaling pathway was downregulated, while the BACE1 expression were upregulated. MgT treatment prevented the impairment of these signaling pathways, stabilized BACE1 expression and reduced SAPP $\beta$ and $\beta$-CTF in the transgenic mice. At the molecular level, elevation of extracellular magnesium prevented the high $A \beta$-induced reductions in synaptic NMDARs by preventing calcineurin overactivation in hippocampal slices.

Conclusions: Our results suggest that elevation of brain magnesium exerts substantial synaptoprotective effects in a mouse model of Alzheimer's disease, and hence it might have therapeutic potential for treating Alzheimer's disease.

Keywords: Alzheimer's disease, Brain magnesium, Synaptoprotection, NMDAR signaling, BACE1

\section{Background}

Dysfunctions in the metabolic processes of amyloid precursor protein (APP) are widely hypothesized to underlie Alzheimer's disease (AD) $[1,2]$. In this scenario, increases in concentration of several potentially toxic peptides including SAPP $\beta$ and $\beta$-CTF [3], N-APP [4] or small A $\beta$ oligomers lead to the formation of $A \beta$-plaques, synapse dysfunction/loss, neuronal loss and overall brain atrophy, which cause decline of cognitive abilities [2,5]. Therefore, designing therapeutic agents that target APP metabolic processes is among the major strategies being pursued in the quest to treat $\mathrm{AD}$ [1]. However, these

\footnotetext{
* Correspondence: liu.guosong@gmail.com

'School of Medicine, Tsinghua University, Beijing, China

Full list of author information is available at the end of the article
}

agents have not been shown to slow/reverse the cognitive deficits in AD patients [1].

Although dysfunctions in APP metabolism are a strong predictor for developing $\mathrm{AD}, \mathrm{A} \beta$-plaque density does not always correlate with the decline in cognitive abilities [6]. For example, some A $\beta$-plaque-positive individuals have no signs of brain atrophy [7], and highly educated subjects seem to tolerate high levels of $A \beta$-plaques without cognitive impairment [8]. Thus, while dysfunctions in APP metabolism might be necessary, it does not appear sufficient for developing $\mathrm{AD}$-associated atrophy and cognitive impairment [9].

Numerous studies demonstrate that elevation of soluble $A \beta$ in the brain could impair synaptic function and reduce synapse density $[2,10]$. However, synaptic plasticity and 
density are regulated by numerous endogenous factors [11], with some having neuro-/synapto-trophic functions. Hence, a balance between APP-derived neurotoxic peptides and neuro-/synapto-trophic factors might ultimately determine the rate of decline in synaptic and cognitive functions in $\mathrm{AD}$. Indeed, several endogenous neurotrophic factors are effective in counteracting the synapse and memory loss in animal models of AD. For example, administration of the peptide cerebrolysin [12], the octapeptide NAP [13], nerve growth factor (NGF) [14], or brain infusion of brain-derived neurotrophic factor (BDNF) [15], in rodent and primate AD models reverses synapse loss or rescues learning and memory. In humans, intranasal administration of insulin improves cognition in early $\mathrm{AD}$ [16]. Therefore, protecting existing synapses and/or promoting synapse generation/regeneration by increasing trophic factors in brain might present an alternative strategy to ameliorate memory deficits in AD.

Our previous studies indicate that the magnesium ion $\left(\mathrm{Mg}^{2+}\right)$ is a critical factor in controlling synapse density/ plasticity [17]. We have shown that elevation of brain magnesium by a novel compound (Mg-L-threonate, MgT) upregulates NMDAR signaling, prevents synapse loss and reverses memory deficits in aged rats [18]. If impairment in cognitive functions in $\mathrm{AD}$ patients is mainly caused by synapse failure/loss [19], it becomes tempting to test whether elevation of brain magnesium could still be effective under AD-like pathological conditions. Furthermore, brain magnesium level [20] and serum $\mathrm{Mg}^{2+}$ concentration [21] appear to be significantly lower in AD patients compared with age-matched normal subjects. If so, then simply restoring brain magnesium might beneficiate $\mathrm{AD}$ patients. Here, we show that elevation of brain magnesium prevents/reverses synapse loss and memory deficits in a transgenic mouse model of $\mathrm{AD}$ and reveal the possible underlying mechanism.

\section{Results}

\section{Elevation of brain magnesium prevented learning and} memory deficits in APPswe/PS1dE9 transgenic mice

We chose the APPswe/PS1dE9 transgenic mouse as an animal model of AD (referred to as $\mathrm{Tg}$ mice) that exhibits high brain amyloid deposits [22] and severe deficits in spatial memory at 6-7 months of age [23-25]. In our previous study in rats, the effective dosage for memory enhancement by $\mathrm{MgT}$ was $50 \mathrm{mg} / \mathrm{kg} /$ day elemental $\mathrm{Mg}$ [18]. The equivalent elemental magnesium dose in mice is $75 \mathrm{mg} / \mathrm{kg} /$ day $(910 \mathrm{mg} / \mathrm{kg} /$ day MgT) [26]. This dose was effective in elevating $\mathrm{Mg}^{2+}$ concentration in plasma and red blood cells (Figure $1 \mathrm{G}$ and $\mathrm{H}$ ). Interestingly, we found that $\mathrm{Mg}^{2+}$ concentration in the plasma of untreated $\mathrm{Tg}$ mice was significantly lower than that of WT mice (Figure 1G), those data are inline with previous studies showing reductions in $\mathrm{Mg}^{2+}$ concentration in the serum of AD patients [21].

We tested whether elevating brain magnesium could prevent learning and memory deficits in $\mathrm{Tg}$ mice. $\mathrm{MgT}$ treatment started at 6 months of age. After 1 month of MgT treatment, we assessed spatial learning and memory abilities using the water maze task. Untreated $\mathrm{Tg}$ mice exhibited unequivocal learning deficits in this task at 7 months of age. MgT-treated $\mathrm{Tg}$ mice $(\mathrm{Tg}+\mathrm{MgT})$, in contrast, performed quite similar to WT (Figure 1A). When we did a probe test $24 \mathrm{~h}$ after the last training trial, untreated Tg mice showed no preference toward the target quadrant, indicating significant memory impairment, while $\mathrm{Tg}+\mathrm{MgT}$ mice performed as well as WT (Figure 1B).

The improvement of cognitive functions after 1 month treatment with $\mathrm{MgT}$ is interesting. However, from therapeutic point of view, efficacy of MgT on cognitive function over a longer time-course is more important. To check if MgT remained effective over a long-term treatment, the same groups of mice were retested at 15 and 22 months of age (after 9 and 16 months of MgT treatment, respectively). At 15 months, learning and memory abilities were reassessed using the same water maze task (modified protocol, see Methods). Tg mice completely lost their ability to locate the hidden platform, while $\mathrm{Tg}+\mathrm{MgT}$ and WT mice could readily locate it (Figure $1 \mathrm{C}$ ). In the probe test, $\mathrm{Tg}+\mathrm{MgT}$ mice, similar to WT, spent significantly more time in the target quadrant compared with other quadrants, while untreated Tg mice swam randomly (Figure 1D). We did not observe significant differences in the velocity, in the water maze, among the three groups of mice at both ages of 7 and 15 months (Table 1), indicating that the differences in latencies/time-in-quadrant among the groups were not because the untreated $\mathrm{Tg}$ mice swam slower than other mice.

At 22 months, we assessed short- and long-term recognition memory (STM and LTM) using a modified version of the standard novel-object recognition task (NORT). The NORT was selected to avoid repeating the water maze task for the third time and because the mice were too weak to perform the water maze task at age of 22 months. During the STM test (10 m retention interval), $\mathrm{Tg}$ mice did not show any preference toward the novel object. In contrast, WT and $\mathrm{Tg}+\mathrm{MgT}$ mice spent significantly more time exploring the novel object (Figure 1E, left). During the LTM test (24 h retention interval) only WT and $\mathrm{Tg}+\mathrm{MgT}$ mice exhibited clear preference toward the novel object (Figure 1E, right). Thus, MgT treatment remained effective after long-term (up to 16 months) treatment.

To confirm that MgT treatment was associated with elevating brain magnesium, we quantified the magnesium contents (total magnesium in tissue) in brain and 

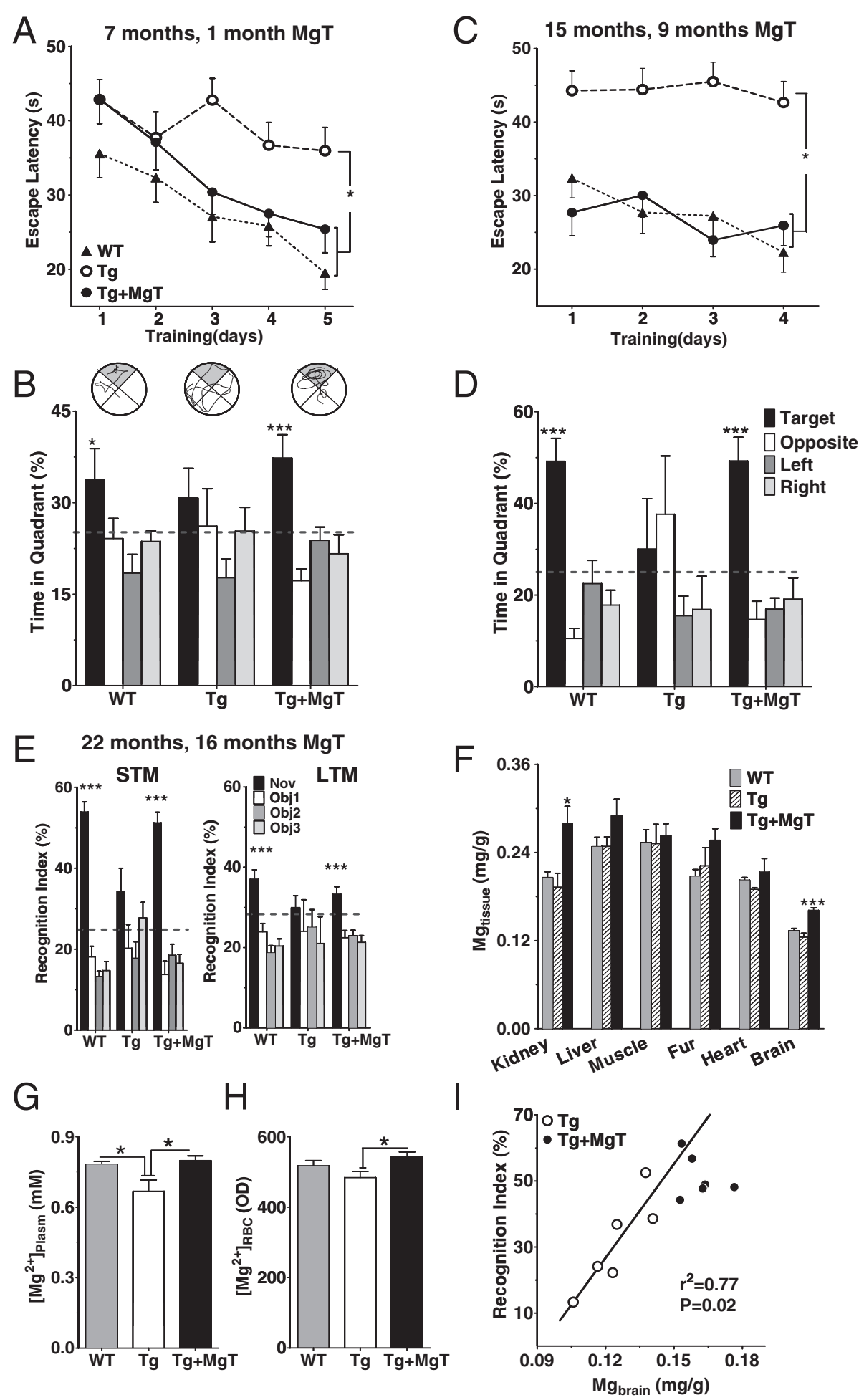

Figure 1 (See legend on next page.) 
(See figure on previous page.)

Figure 1 Prevention of memory deficits in APPswe/PS1dE9 transgenic mice (Tg mice) by MgT treatment. (A) Escape latencies in seconds(s) during training (5 trials/day) in water maze task at 7 months of age, i.e., after 1 month of treatment. Three groups of mice were used; WT $(n=9), \operatorname{Tg}(n=13)$ and $\mathrm{Tg}+\operatorname{MgT}(n=9$; ANOVA effect of treatment, $p<0.05)$. (B) Probe test conducted $24 \mathrm{~h}$ after the training. Top, representative path tracings. Bottom, percentage of time spent in each quadrant (ANOVA differences among quadrants; WT: $p<0.05 ; \mathrm{Tg}+\mathrm{MgT}$ : $p<0.0001$ ).

(C) Same as (A) and on the same mice, but tested at 15 months of age. WT $(n=9)$; $\mathrm{Tg}(n=7) ; \mathrm{Tg}+\mathrm{MgT}(n=6)$. ANOVA effect of treatment $p<0.05$. (D) Probe test $24 \mathrm{~h}$ later (ANOVA differences among quadrants: WT: $p<0.0001$; Tg + MgT: $p<0.0001)$. (E) Short-term (10 m in retention interval, left) and long-term (24 h, right) novel-object recognition memory tests performed on the same group of mice at 22 months of age. WT ( $n=7)$, Tg $(n=6)$, and $\mathrm{Tg}+\operatorname{MgT}(n=6)$. Recognition index calculated as percentage of time spent exploring each object (Obj1-3). Black bars indicate novel object (Nov). ANOVA differences in recognition index of different objects in WT (STM: $p<0.0001$; LTM: $p<0.0001)$ and Tg + MgT (STM: $p<0.0001$; LTM: $p<0.001)$. Dashed lines represent chance levels of performance (25\%). (F) Total magnesium (ionized and non-ionized) contents in different organs/tissues $\left(\mathrm{Mg}_{\text {tissue }}\right)$ normalized to tissue weight $(\mathrm{mg} / \mathrm{g})$ in the same groups of mice. WT $(n=7)$, Tg $(n=6)$ and Tg + MgT $(n=6)$. ANOVA difference among groups (brain: $p<0.0001$; kidney: $p<0.01)$. (G) Magnesium ion concentration in the plasma $\left(\left[\mathrm{Mg}{ }^{2+}\right]_{\text {plasma, }} \mathrm{mM}\right)$ of WT $(\mathrm{n}=14)$, Tg $(\mathrm{n}=9)$ and $\mathrm{Tg}+\mathrm{MgT}$ mice $(\mathrm{n}=8)$ as measured by the calmagite method. ANOVA difference among groups $(p<0.01)$. $(\mathbf{H})$ The intracellular free Mg ${ }^{2+}$ concentration in the red blood cell $\left(\left[\mathrm{Mg}^{2+}\right]_{\mathrm{RBC}}\right)$ of WT $(n=12), \mathrm{Tg}(\mathrm{n}=11)$ and $\mathrm{Tg}+\mathrm{MgT}$ mice $(\mathrm{n}=11)$ as measured by the flow cytometry method (fluorescent optical density, OD). ANOVA difference among groups ( $p<0.05)$. ANOVA was followed by Bonfferoni's post hoc test. (I) Brain total magnesium content (Mgbrain, $\mathrm{mg} / \mathrm{g}$ ), in Tg mice (23 months old), significantly correlated with the recognition index in the short-term recognition memory test (Pearson's test). Data from Tg + MgT mice (23 months old treated for 17 months) are displayed, but were not included in the correlation analysis. Error bars show SEM. ${ }^{*} p<0.05,{ }^{* * *} p<0.001$.

in other organs in the behaviorally tested mice mentioned above (perfused at age of 23 month). MgT treatment selectively elevated $\mathrm{Mg}^{2+}$ content in brain and kidneys (Figure $1 \mathrm{~F}$ ) of $\mathrm{Tg}$ mice. Interestingly, in untreated Tg mice, brain magnesium level positively correlated with their cognitive function; the lower their brain magnesium, the poorer their memory function in the NORT task (Pearson's test, $r^{2}=0.77, p=0.02$, Figure $1 \mathrm{I}$ ). We did not observe significant side effects over the entire time-course of MgT treatment (Table 1).

\section{Elevation of brain magnesium prevented synapse loss in APPswe/PS1dE9 transgenic mice}

To study the cellular mechanisms underlying the prevention of memory deficits in Tg mice by MgT, we examined effects of this treatment on synapse density. The brains of the same mice used in the above-described behavioral experiments (Figure 1) were subjected to histological analysis. First, we quantified synapse density in the hippocampus, a brain region critical for memory function. Tg mice had a significantly lower number of synapses (by $\sim 25.3 \%$ ) compared to WT; this synapse loss was prevented by $\mathrm{MgT}$ treatment (Figure 2A, for ANOVA analysis see Table 2). We also checked the total presynaptic terminal density, using the synaptic vesicle marker synaptophysin, in the hippocampal dentate gyrus (DG). In Tg mice there were significantly fewer synaptic puncta $(\sim 32.5 \%)$ than those in WT mice. MgT treatment prevented this reduction in $\mathrm{Tg}$ mice (Figure $2 \mathrm{~B}$ and Table 2).

Next, we examined the effects of MgT treatment on GABAergic terminals by quantifying density of glutamic acid decarboxylase $65 \mathrm{kD}$ (GAD65) labeled puncta. Tg mice had significantly lower immunostained puncta density for GAD65 ( 33.3\%, Figure $2 \mathrm{C}$ and Table 2$)$ than WT. MgT treatment prevented the loss in GABAergic terminals (Figure $2 \mathrm{C}$ ).

To determine the functional consequences of synapse density reduction on glutamatergic synaptic transmission, we compared the input-output relationship of hippocampal CA1 synapses in vivo, in a separate group of mice (15 months old, MgT treatment for 9 months). The amplitude of field postsynaptic potentials (fPSPs) for a given stimulus intensity was significantly lower in Tg mice compared to WT, while Tg + MgT mice had a similar input-output relationship as WT (Figure 2D). Therefore, MgT treatment was also effective in preventing reductions in glutamatergic synaptic transmission.

Finally, we plotted the relationship between synapse density and short-term memory (quantified by the

Table 1 Body weight, food/fluid intake, and locomotor activity in the open field of wild-type (WT, $n=7), T g(n=6)$ and $\mathrm{Tg}+\operatorname{MgT}(n=6)$ mice and the velocity in the water maze task of WT, Tg and Tg + MgT mice at age of 7 months ( $n=9$, 13, 9; respectively) and 15 months $(n=9,7,6$; respectively)

\begin{tabular}{|c|c|c|c|c|c|c|c|}
\hline \multirow{2}{*}{$\begin{array}{l}\text { Group } \\
\text { of mice }\end{array}$} & \multirow{2}{*}{$\begin{array}{l}\text { Body } \\
\text { weight (g) }\end{array}$} & \multirow{2}{*}{$\begin{array}{l}\text { Food intake } \\
\text { (g/day) }\end{array}$} & \multirow{2}{*}{$\begin{array}{l}\text { Fluid intake } \\
\text { (ml/day) }\end{array}$} & \multicolumn{2}{|c|}{ Locomotor activity in the open field } & \multicolumn{2}{|c|}{ Velocity in the water maze $(\mathrm{cm} / \mathrm{s})$} \\
\hline & & & & Velocity $(\mathrm{cm} / \mathrm{s})$ & Distance travelled $(\mathrm{cm})$ & 7 months old & 15 months old \\
\hline$\pi$ & $42.84 \pm 3.92$ & $4.08 \pm 0.61$ & $7.16 \pm 0.26$ & $5.72 \pm 0.75$ & $3403.99 \pm 443.13$ & $11.2 \pm 1.1$ & $12.9 \pm 2.6$ \\
\hline $\mathrm{Tg}$ & $40.87 \pm 10.80$ & $3.41 \pm 1.48$ & $6.83 \pm 0.71$ & $4.34 \pm 0.48$ & $2573.52 \pm 286.99$ & $9.9 \pm 1.1$ & $11.1 \pm 1.9$ \\
\hline $\mathrm{Tg}+\mathrm{MgT}$ & $39.73 \pm 3.57$ & $3.69 \pm 0.74$ & $6.25 \pm 1.00$ & $5.03 \pm 0.32$ & $2954.00 \pm 159.68$ & $10.8 \pm 1.5$ & $11.8 \pm 2.4$ \\
\hline
\end{tabular}

On way ANOVA revealed no significant differences among the three groups of mice. Data presented as mean \pm SD. 


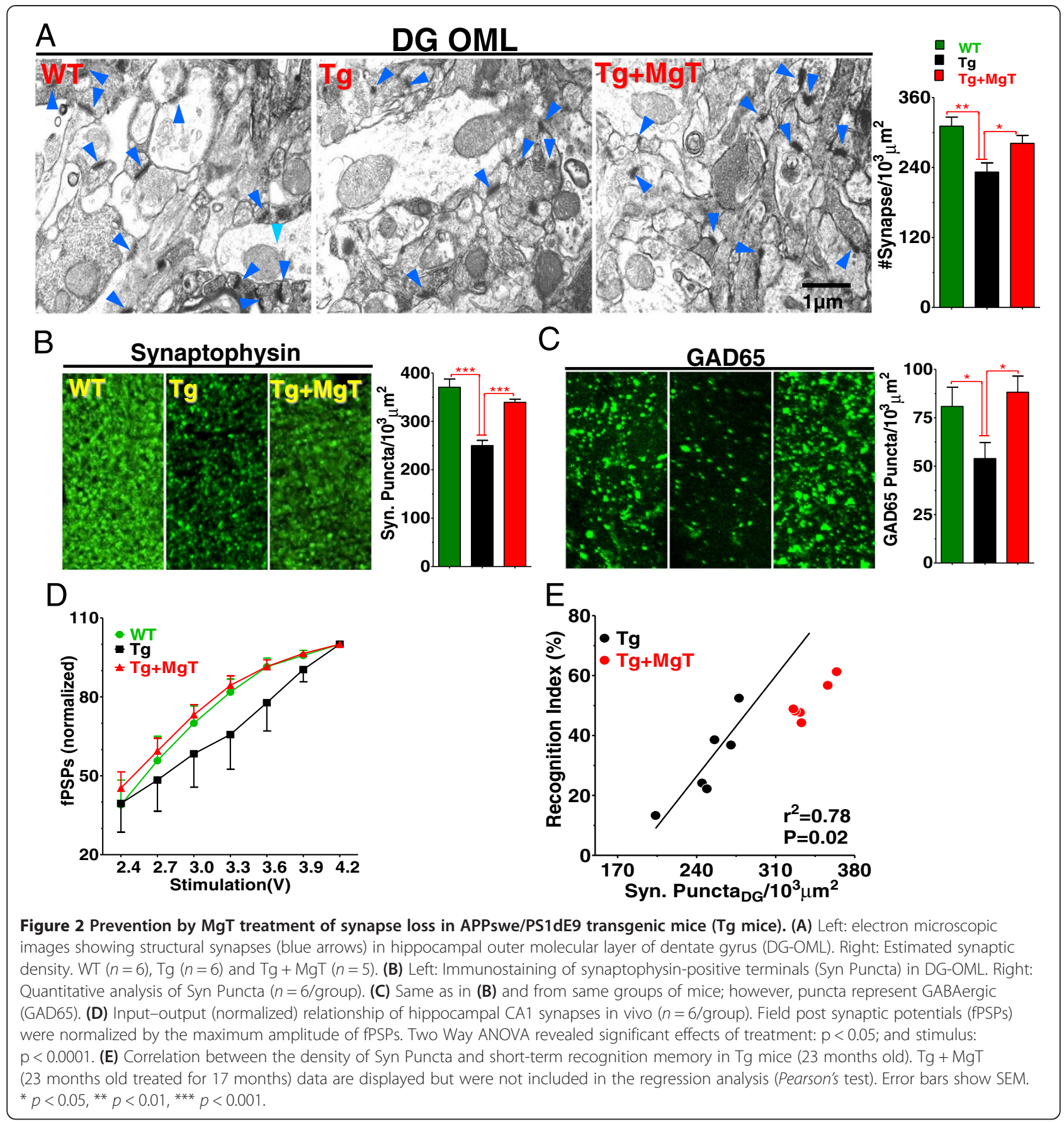

recognition index during NORT task) in Tg mice. Memory performance correlated with the density of synaptophysin puncta $\left(r^{2}=0.78, p=0.02\right.$, Figure $\left.2 \mathrm{E}\right)$, suggesting that synapse loss might be one of primary factors underlying memory deficits in Tg mice.

\section{Impairment of NMDAR signaling in APPswe/PS1dE9} transgenic mice

During learning and memory processes, correlated synaptic inputs activate NMDARs, leading to activation of downstream signaling molecules and increase in expression of genes necessary for synaptic remodeling [27]. Having demonstrated that $\mathrm{Tg}$ mice have significant reductions in structural synapse density and glutamatergic synaptic transmission, we next evaluated whether activation of NMDAR signaling still occurs in the remaining synapses following environmental enrichment behavioral stimulation. The environmental enrichment-based stimulus was chosen because it will evoke physiologic neuronal inputs. 
Table 2 One-way ANOVA analysis of the electron microscopy, immunostaining and Western blot data

\begin{tabular}{|c|c|c|c|c|c|c|}
\hline \multirow{2}{*}{$\begin{array}{l}\text { Value } \\
\text { Protein }\end{array}$} & \multicolumn{3}{|c|}{ Basal } & \multicolumn{3}{|c|}{ Stimulation } \\
\hline & $F$ value & $P$ value & Figure & F value & $P$ value & Figure \\
\hline Structural synapses & $F_{(2,14)}=7.243$ & 0.0069 & Figure $2 \mathrm{~A}$ & NA & NA & NA \\
\hline Synaptophysin & $\mathbf{F}_{(2,15)}=26.21$ & $<0.0001$ & Figure 2B & NA & NA & NA \\
\hline GAD65 & $\mathbf{F}_{(2,15)}=4.130$ & 0.0373 & Figure 2D & NA & NA & NA \\
\hline NR2B/GAPDH & $\mathbf{F}_{(2,12)}=1.026$ & 0.3877 & Figure 3B & $\mathbf{F}_{(2,14)}=55.26$ & $<0.0001$ & Figure 3B \\
\hline pCamkll/Camkll & $\mathbf{F}_{(2,12)}=0$ & 1 & Figure $3 C$ & $\mathbf{F}_{(2,14)}=4.269$ & 0.0357 & Figure $3 C$ \\
\hline pCreb/Creb & $\mathbf{F}_{(\mathbf{2}, \mathbf{1 2})}=0$ & 1 & Figure 3D & $F_{(\mathbf{2}, \mathbf{1 4})}=9.883$ & 0.0021 & Figure 3D \\
\hline BACE1/GAPDH & $F_{(2,12)}=28.70$ & $<0.0001$ & Figure $5 \mathrm{C}$ & $\mathbf{F}_{(2,14)}=60.76$ & $<0.0001$ & Figure $5 C$ \\
\hline Synaptophysin & NA & NA & NA & $F_{(2,16)}=20.15$ & $<0.0001$ & Figure $7 \mathrm{~F}$ \\
\hline
\end{tabular}

NA: not applicable.

We prepared new groups of mice (sacrificed at age of 18 month, MgT treatment was given for 12 months) and compared the expression/phosphorylation of NMDAR signaling key proteins using quantitative Western blotting. Mice from each group were divided into two halves, one half was sacrificed under home-cage conditions (basal) and the second half was sacrificed following $24 \mathrm{~h}$ of environmental enrichment-based stimulation. Under basal conditions, the NMDAR signaling appeared to be identical between WT and $\mathrm{Tg}$ mice. Interestingly, environmental stimulation induced increases in NR2B expression (by 167\%, Figure 3A and B), CaMKII activation (pCaMKII, by $129 \%$, Figure $3 \mathrm{~A}$ and $\mathrm{C}$ ) and in CREB activation (pCREB, by 399\%, Figure 3A and D) in WT but not in $\mathrm{Tg}$ mice. MgT treatment rescued these deficits (Figure 3 and Table 2). Thus, dysfunction of APP metabolism not only triggered synapse loss and reduction of synaptic transmission, but also impaired activation of NMDAR signaling by correlated synaptic inputs, which might result in loss of the plasticity in the remaining synapses. The expression/activation pattern of NMDAR signaling in $\mathrm{Tg}+\mathrm{MgT}$ mice was almost identical to WT, in both basal and stimulated conditions. Therefore, MgT treatment might protect NMDAR signaling necessary for synaptic plasticity following neuronal activity.

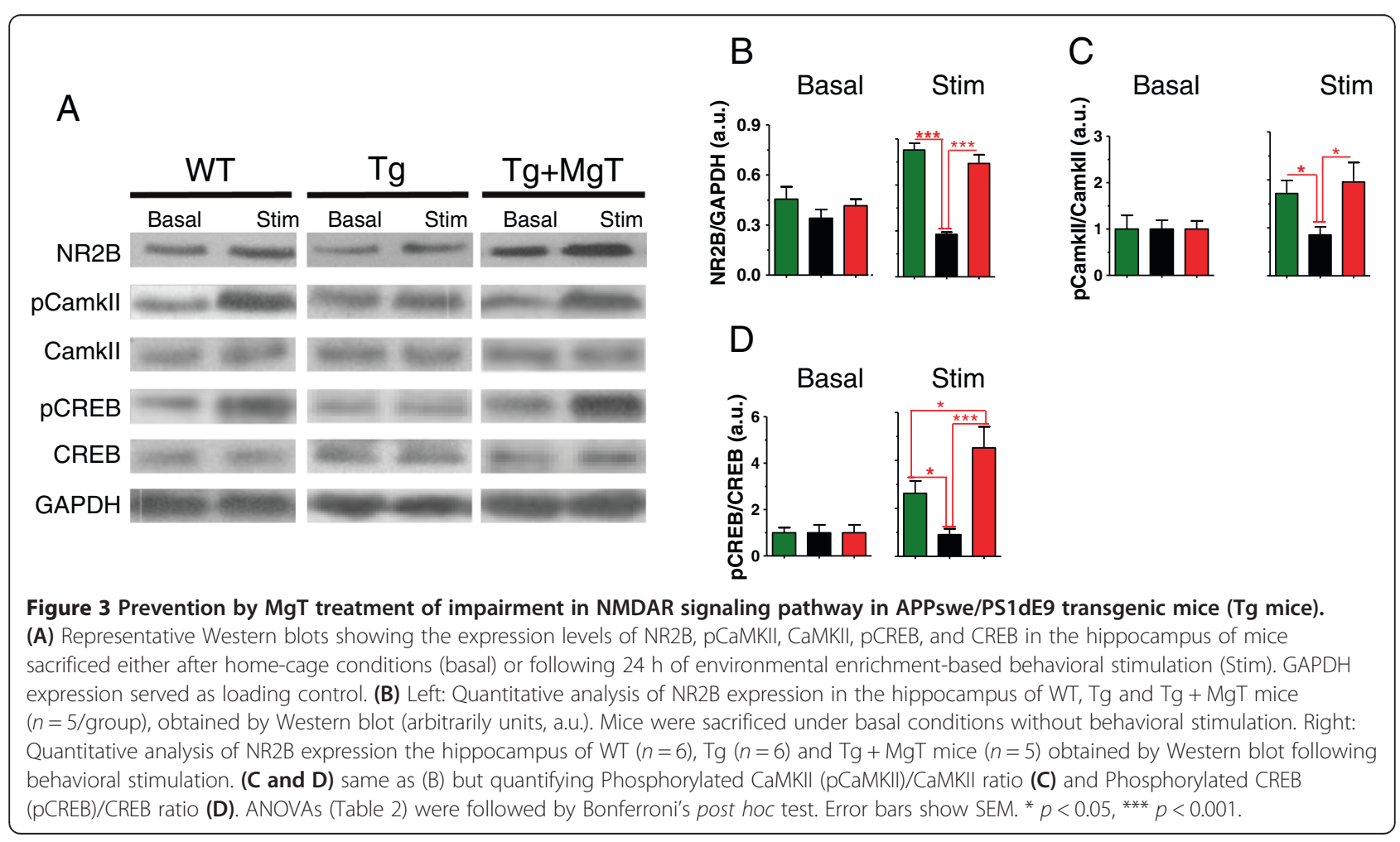


Prevention of exogenous $A \beta 42$-induced downregulation of NMDAR synaptic transmission by elevation of $\left[\mathrm{Mg}^{2+}\right]_{0}$ It is clear that MgT treatment not only prevented synapse loss in Tg mice, but also restored the functionality of NMDAR signaling in the remaining synapses. Since NMDARs are essential for synaptic plasticity and memory functions, we conducted the following experiments to explore, mechanistically, how elevation of $\mathrm{Mg}^{2+}$ can protect NMDARs from $A \beta$-induced downregulation.

First, we studied the molecular mechanisms underlying impairment of NMDARs by $\mathrm{A} \beta$. The $\mathrm{EPSC}_{\mathrm{NMDA}}$ /
EPSC $_{\text {AMPA }}$ between CA3-CA1 synaptic connections (Shaffer collaterals) was recorded in hippocampal slices using whole-cell patch-clamp recordings from CA1 pyramidal neurons while stimulating Shaffer collaterals at low frequency $(0.03 \mathrm{~Hz})$. Exogenous application of $\mathrm{A} \beta$ (1 $\mu \mathrm{M}$ for $1 \mathrm{~h}$ at room temperature) significantly reduced $\mathrm{I}_{\mathrm{NMDA}}$ (by $48 \%$ ), when brain slices were bathed under physiological extracellular magnesium concentration $\left(\left[\mathrm{Mg}^{2+}\right]_{\mathrm{o}}=0.8 \mathrm{mM}\right.$, referred to as $0.8-\left[\mathrm{Mg}^{2+}\right]_{\mathrm{o}}$ slices, Figure 4B). A previous study suggests that downregulation of NMDARs by exogenous $A \beta$ is likely mediated by

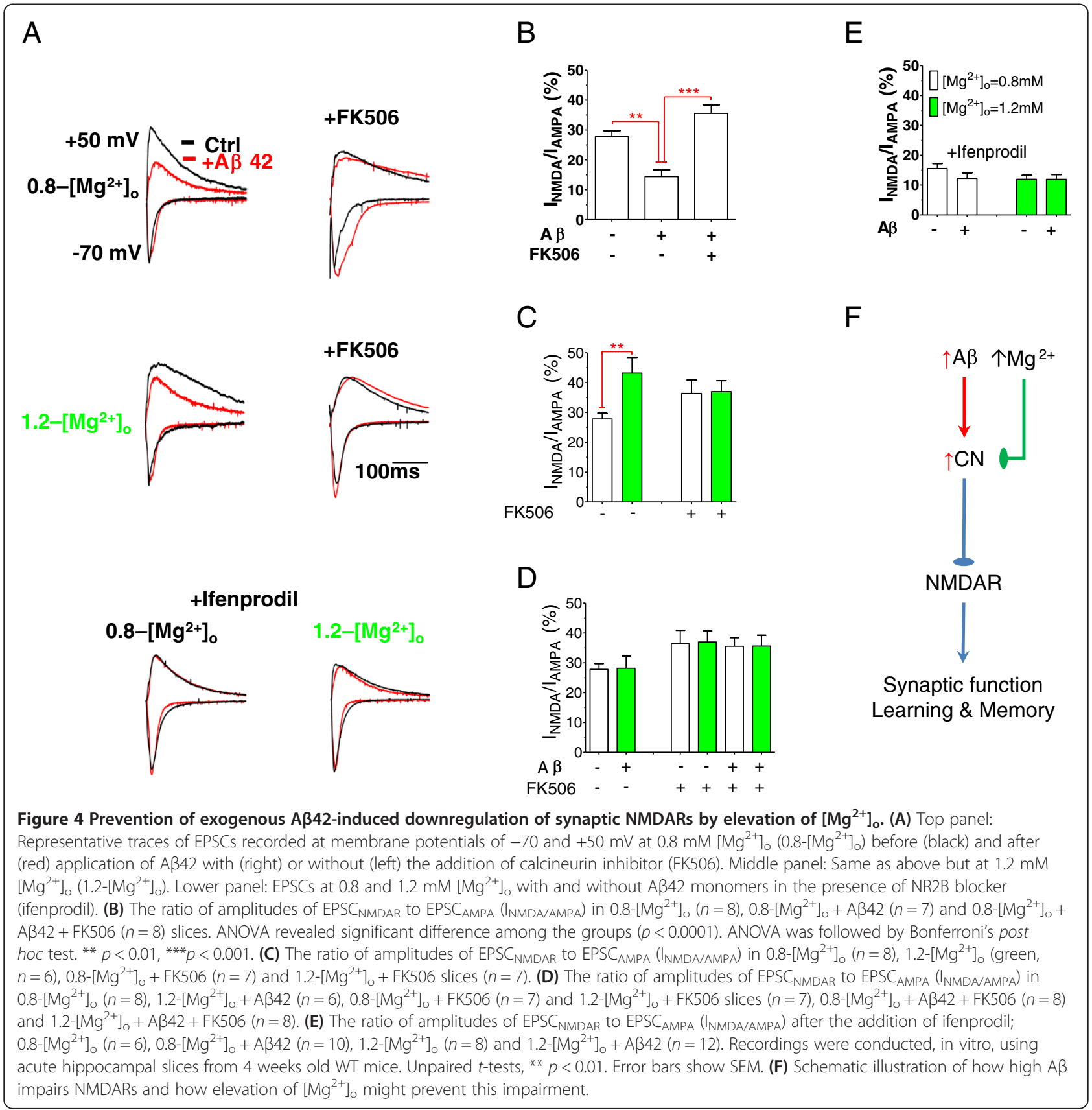


overactivation of calcineurin [28]. We confirmed their observations and found that inhibition of calcineurin (FK506, $10 \mu \mathrm{M}$ for $1 \mathrm{~h}$ ) was effective in preventing downregulation of NMDARs by $A \beta$ in hippocampal slices (Figure 4B). Therefore, calcineurin might be the molecular target mediating the $\mathrm{A} \beta$-induced downregulation of NMDARs.

Next, we tested whether calcineurin is also involved in the molecular mechanism underlying the upregulation of NMDARs by elevation of $\left[\mathrm{Mg}^{2+}\right]_{\mathrm{o}}[17,18]$. As expected, elevation of $\left[\mathrm{Mg}^{2+}\right]_{\mathrm{o}}$ (to $1.2 \mathrm{mM}, 1.2-\left[\mathrm{Mg}^{2+}\right]_{\mathrm{o}}$ slices), increased $\mathrm{I}_{\mathrm{NMDA}}$ (by $\sim 53 \%$, percentage of $0.8-\left[\mathrm{Mg}^{2+}\right]_{\mathrm{o}}$ slices, Figure $4 \mathrm{C}$ ). Interestingly, in the presence of the calcineurin inhibitor, $\mathrm{I}_{\mathrm{NMDA}}$ increased in $0.8-\left[\mathrm{Mg}^{2+}\right]_{\mathrm{o}}$ (Figure $4 \mathrm{C}$ ), while $\mathrm{I}_{\mathrm{NMDA}}$ in $1.2-\left[\mathrm{Mg}^{2+}\right]_{\mathrm{o}}$ remained the same such that the amplitudes of $\mathrm{I}_{\mathrm{NMDA}}$ under $0.8-\left[\mathrm{Mg}^{2+}\right]_{\mathrm{o}}$ and $1.2-\left[\mathrm{Mg}^{2+}\right]_{0}$ slices were almost identical (Figure $4 \mathrm{C}$ ). Those data imply that elevation of $\left[\mathrm{Mg}^{2+}\right]_{0}$ might upregulate $\mathrm{I}_{\mathrm{NMDA}}$ by inhibiting calcineurin signaling. If both $\mathrm{A} \beta$ and $\left[\mathrm{Mg}^{2+}\right]_{\mathrm{o}}$ influence $\mathrm{I}_{\mathrm{NMDA}}$ by controlling the activity of calcineurin, then elevation of brain magnesium might be able to prevent overactivation of calcineurin by high $A \beta$, resulting in protection of NMDARs. Indeed, in the presence of higher $\left[\mathrm{Mg}^{2+}\right]_{\mathrm{o}}$ $(1.2 \mathrm{mM})$, the amplitude of $\mathrm{I}_{\mathrm{NMDA}}$ current under exogenous $A \beta$ was almost identical to that in $0.8-\left[\mathrm{Mg}^{2+}\right]_{0}$ control slices (incubated under $\mathrm{A} \beta$ free and physiological $\left[\mathrm{Mg}^{2+}\right]_{0}$ conditions, Figure 4D). To prove that this protection is mediated by calcineurin, we compared the size of $\mathrm{I}_{\mathrm{NMDA}}$ under high $\mathrm{A} \beta$, high/low $\left[\mathrm{Mg}^{2+}\right]_{\mathrm{o}}$, or both in the presence of calcineurin inhibitor. $\mathrm{I}_{\mathrm{NMDA}}$ was identical in all slices regardless of the presence of high $\mathrm{A} \beta$ or $\left[\mathrm{Mg}^{2+}\right]_{\mathrm{o}}$ (Figure 4D). Thus, elevation of brain magnesium might protect NMDARs in the Tg mice by preventing over-activation/-expression of calcineurin (Figure 4F).

Finally, we studied the effects of $A \beta$ on $I_{\mathrm{NMDA}}$ after blocking NR2B-containing NMDARs with ifenprodil (3 $\mu \mathrm{M}$ for $10 \mathrm{~m}$ before recording). NR2A-containing NMDARs in 0.8- and 1.2- $\left[\mathrm{Mg}^{2+}\right]_{\mathrm{o}}$ slices were unaffected by $A \beta$ (Figure $4 \mathrm{E}$ ), suggesting that the reduction of $\mathrm{I}_{\mathrm{NMDA}}$ after $A \beta$ application was largely due to reduction of synaptic NR2B-portion of NMDARs, whereas elevated $-\left[\mathrm{Mg}^{2+}\right]_{\text {o }}$ prevented this downregulation.

\section{Effects of elevating brain magnesium on amyloid plaques and BACE1 expression}

Having demonstrated that elevating brain magnesium can protect NMDAR signaling, we explored whether elevation of brain magnesium can affect APP metabolism, which might also contribute to the retained cognitive abilities in MgT-treated Tg mice. We, first, quantified amyloid plaques density, using the anti-A $\beta$-antibody $6 \mathrm{E} 10$, in the hippocampus and frontal cortex. At 23 months of age, $12 \%$ of the hippocampal area in $\mathrm{Tg}$ mice was occupied by amyloid plaques. MgT treatment (for 17 months) reduced the amyloid plaque area significantly (by $\sim 35.8 \%$, Figure $5 \mathrm{~A}$, upper panel). A similar percentage of reduction was observed in the frontal cortex (by $\sim 36 \%$, Figure $5 \mathrm{~A}$, lower panel). These observations were confirmed by another anti-A $\beta$-antibody (4G8, data not shown). We checked the concentrations of $A \beta 42$ and $A \beta 40$ monomers in the cerebrospinal fluid (CSF) of a separate group of Tg mice (14 months old, MgT treatment for 8 months). The concentration of $A \beta 42$ was elevated in the CSF of Tg mice. Surprisingly, despite the significant reduction in the amyloid plaques density, CSF concentration of both $A \beta$ monomers was unaltered by MgT treatment (Figure 5B).

To study the molecular mechanisms underlying the reduction of amyloid plaques by $\mathrm{MgT}$ treatment, we investigated the expression of $\beta$-secretase (BACE1) in the three groups of mice using quantitative Western blot analysis (brain homogenates from same mice in Figure 3, see the Additional file 1: Figure S1 and Additional file 2: Figure S2 for the raw data). Under home-cage and following environmental enrichment-based stimulation, $\mathrm{Tg}$ mice had significantly higher BACE1 expression levels than WT mice (Figure 5C). Interestingly, MgT treatment prevented overexpression of BACE1 under both basal and stimulated conditions in $\mathrm{Tg}$ mice (Figure $5 \mathrm{C}$ and Table 2). To check if the reductions in BACE1 by MgT lead to reductions in the synaptotoxic products of BACE1; namely sAPP $\beta$ and $\beta$-CTF [3], we investigated the expression of human $\mathrm{SAPP} \beta$ and $\beta$-CTF in Tg and $\mathrm{Tg}+\mathrm{MgT}$ mice. We found that $\mathrm{Tg}+\mathrm{MgT}$ mice had significantly lower SAPP $\beta$ expression levels than untreated $\mathrm{Tg}$ mice following environmental enrichment-based stimulation (Figure 5D). Quantitative Western blot analysis also showed that $\mathrm{Tg}+\mathrm{MgT}$ mice had significantly lower $\beta$-CTF levels than untreated Tg mice under basal conditions (Figure 5E). Thus, MgT treatment might reduce the production of APP synaptotoxic metabolites by stabilizing the expression of BACE1 in Tg mice. These results uncover a new and intriguing potential molecular target of elevated brain magnesium in APP metabolism.

We have previously shown that MgT treatment upregulates NR2B-containing NMDARs signaling and increases synapse density in the hippocampus of wild type young and aged rats [18]. The intriguing stabilization of BACE1 expression by MgT prompted us to investigate if this effect of $\mathrm{MgT}$ is specific to the $\mathrm{Tg}$ mice or $\mathrm{MgT}$ might also regulate BACE1 expression in WT mice. We quantified the expression of BACE1 and NR2B (as a positive control) in WT mice treated with MgT (sacrificed at age of 18 month, MgT treatment was given for 12 months). Mice were sacrificed under basal (home-cage) conditions or following environmental enrichment-based stimulation. As expected, MgT treatment upregulated 
B

A

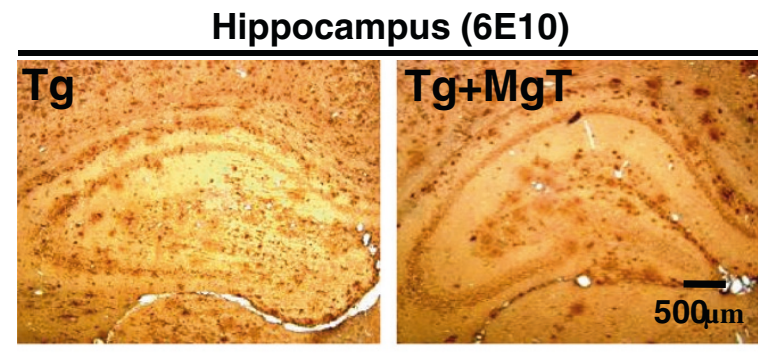

Frontal Cortex (6E10)
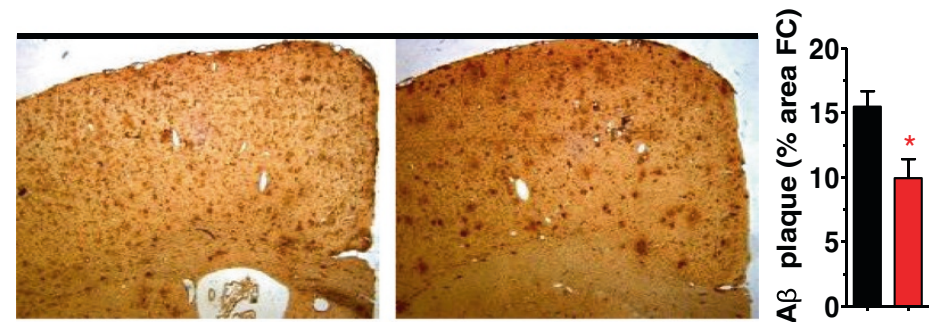

C

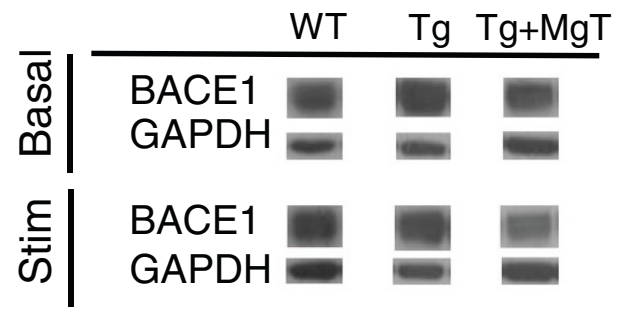

D

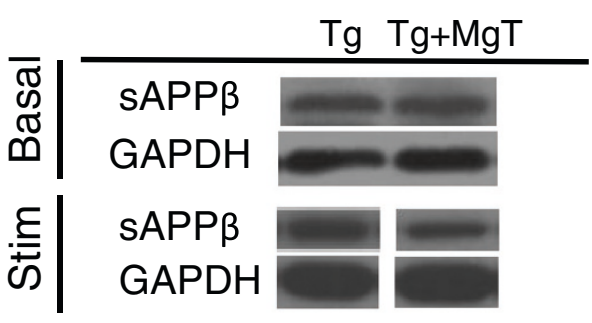

E

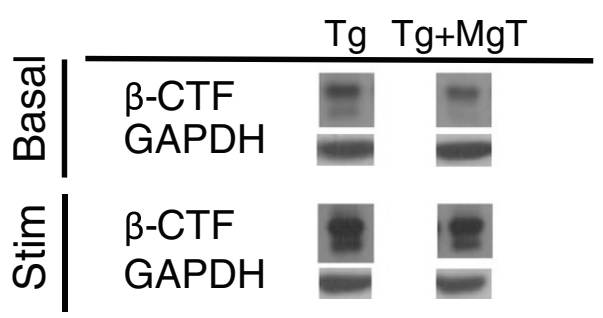

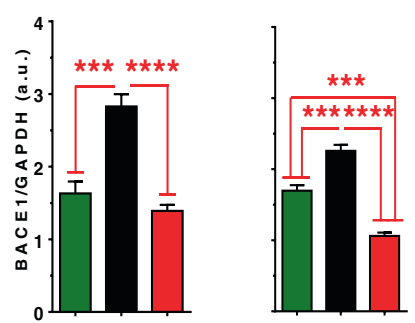
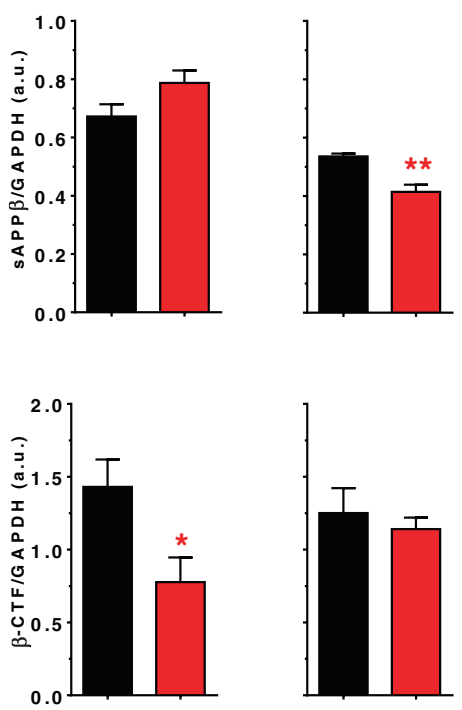
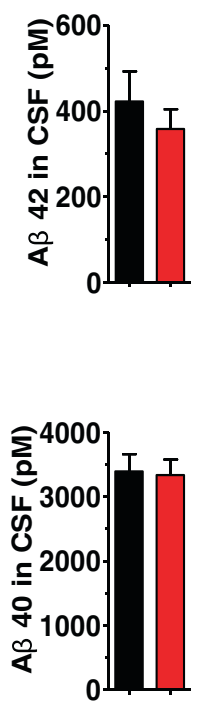
(See figure on previous page.)

Figure 5 Reductions by MgT treatment in amyloid plaques and BACE1 overexpression in APPswe/PS1dE9 transgenic mice (Tg mice). (A) Upper panel left: Immunostaining of hippocampal amyloid plaque of $\operatorname{Tg}(n=6)$ and $\operatorname{Tg}+\operatorname{MgT}(n=5)$. Right: Hippocampal amyloid plaque areas were significantly lower in $\mathrm{Tg}+\mathrm{MgT}$ mice. Lower panel: same as above but in the frontal cortex. Two tailed unpaired $t$-test, ${ }^{*} p<0.05$. (B) Concentrations of A 42 (upper panel) and AB40 (lower panel) monomers in CSF of Tg $(n=13)$ and $\mathrm{Tg}+\operatorname{MgT}(n=15)$ measured by ELISA. (C) Left: Representative Western blots of BACE1 ( $\beta$-secretase) expression in the hippocampus of mice sacrificed under home-cage conditions (basal) or following $24 \mathrm{~h}$ of environmental enrichment-based stimulation (Stim). Middle: Quantitative analysis of BACE1 expression in the hippocampus of $\mathrm{WT}, \mathrm{Tg}$ and $\mathrm{Tg}+\mathrm{MgT}$ mice ( $n=5 /$ group) obtained by Western blot (arbitrarily units, a.u.). Mice were sacrificed under basal conditions without behavioral stimulation. Right: Quantitative analysis of BACE1 expression in the hippocampus of WT $(n=6), \operatorname{Tg}(n=6)$ and $\operatorname{Tg}+\operatorname{Mg} \mathrm{T}$ mice $(n=5)$ obtained by Western blots following behavioral stimulation. ANOVAs (Table 2) were followed by Bonferroni's post hoc test. (D) Left: Representative Western blots of hSAPP $\beta$ expression in the hippocampus of mice sacrificed under home-cage conditions (basal) or following $24 \mathrm{~h}$ of environmental enrichment-based stimulation (Stim). Middle: Quantitative analysis of hsAPP $\beta$ expression in the hippocampus of Tg and Tg + MgT mice ( $n=5 / g r o u p)$ obtained by Western blot (arbitrarily units, a.u.). Mice were sacrificed under basal conditions without behavioral stimulation. Right: Quantitative analysis of hsAPP $\beta$ expression in the hippocampus of $\mathrm{Tg}(n=6)$ and $\mathrm{Tg}+\operatorname{Mg} \mathrm{T}$ mice $(n=5)$ obtained by Western blots following behavioral stimulation. (E) Same as (D) but for $\beta$-CTF, Tg $(n=3)$ obtained by Western blots following behavioral stimulation. Two tailed unpaired $t$-tests. Data from WT mice was displayed but not included in the analysis. Error bars show SEM. ${ }^{*} p<0.05,{ }^{* *} p<0.01,{ }^{* * *} p<0.001$.

NR2B expression in the hippocampus of WT mice (Figure 6A). However, BACE1 expression was indifferent between WT and WT + MgT mice under basal conditions and following behavioral stimulation (Figure 6B). These results suggest that elevation of brain magnesium stabilizes BACE1 expression only in the Tg mice.
Reversal of learning and memory deficits and synapse loss in aged APPswe/PS1dE9 transgenic mice by MgT treatment

Our previous study demonstrates that elevation of brain magnesium can promote synaptogenesis and enhance NMDAR signaling in aging rats [18]. If synapse loss and
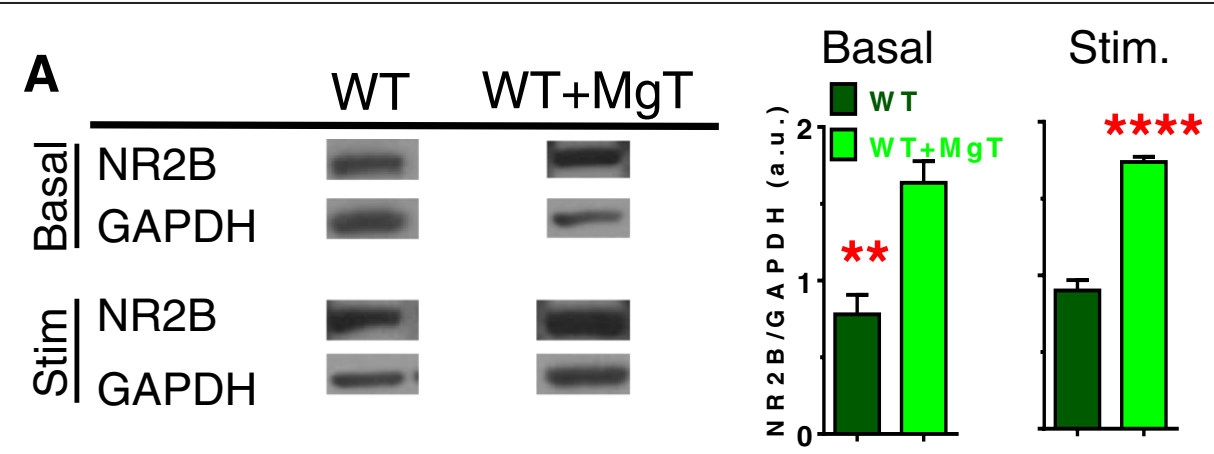

B
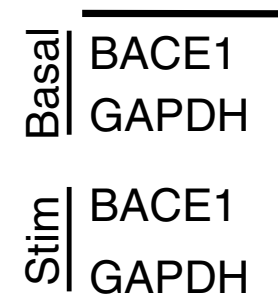
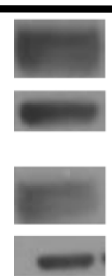
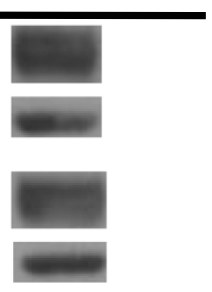
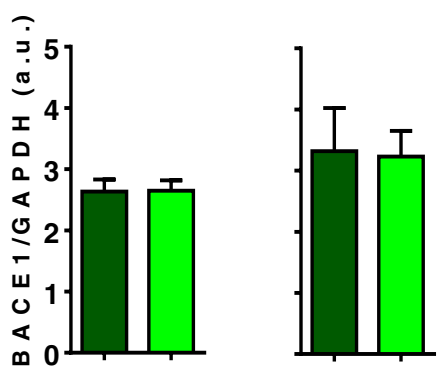

Figure 6 Effects of MgT treatment on expression of NR2B and BACE1 in wild type mice. (A) Left: Representative Western blots of NR2B expression in the hippocampus of WT mice sacrificed under home-cage conditions (basal) or following $24 \mathrm{~h}$ of environmental enrichment-based stimulation (Stim.). Middle: Quantitative analysis of NR2B expression in the hippocampus of WT and WT + MgT mice $(n=5 /$ group) obtained by Western blot (arbitrarily units, a.u.). Mice were sacrificed under basal conditions without behavioral stimulation. Right: Quantitative analysis of NR2B expression in the hippocampus of WT and WT + MgT mice ( $n=6 /$ group) obtained by Western blots following behavioral stimulation. (B) Left: Representative Western blots of BACE1 ( $\beta$-secretase) expression in the hippocampus of WT mice sacrificed under home-cage conditions (basal) or following $24 \mathrm{~h}$ of environmental enrichment-based stimulation (Stim.). Middle: Quantitative analysis of BACE1 expression in the hippocampus of WT and WT + MgT mice ( $n=5$ /group) obtained by Western blot (arbitrarily units, a.u.). Mice were sacrificed under basal conditions without behavioral stimulation. Right: Quantitative analysis of BACE1 expression in the hippocampus of WT and WT + MgT mice $(n=6 / \mathrm{group})$ obtained by Western blots following behavioral stimulation. Two tailed unpaired $t$-test. Error bars show SEM. ${ }^{*} p<0.05$. 
dysfunction in NMDAR signaling in AD is also reversible, MgT treatment should be effective in reversing memory deficits even when it is given at the end-stage of AD-like pathological progression in Tg mice. To test this possibility, we prepared another group of untreated $\mathrm{Tg}$, tested their memory abilities at 23 month of age, treated them with MgT (1 month) and reevaluated their memory abilities. As expected, before treatment, $\mathrm{Tg}$ mice did not show any preference toward the novel object in the STM and LTM tests, in contrast to aged WT (Figure 7A and B). After 1 month of MgT treatment, strikingly, the same $\mathrm{Tg}$ mice exhibited significant improvement in their performance on the memory tests (Figure 7A and C). To further prove that $\mathrm{MgT}$ treatment is effective in restoring cognitive abilities in end-stage Tg mice, we evaluated the nest construction abilities (a social behavior) in Tg mice before and after MgT treatment in a separate group of mice (23 months old). Before MgT treatment, the Tg mice exhibited significant impairment in nest construction behavior compared with aged WT $(p<0.05$, Figure 7D). Following only 1 month of MgT treatment, nest construction behavior was restored in Tg mice $(p=0.2$, Figure 7E). These data demonstrate that learning and memory deficits in the $\mathrm{Tg}$ mice might be reversible even at the end-stage of AD-like pathological progression. However, we like to point out a limitation of the above behavioral experiments: the number of animals is relatively low such that the conclusion drawn from these behavioral data might be subjected to potential statistical errors. The lower number of animal in the above experiments was due to poor survival of $\mathrm{Tg}$ mice during aging (see below), although we prepared a large number of mice at the beginning of the experiments (see Methods). We took two measures to reduce the potential statistical errors. First, cognitive functions were evaluated by using different behavioral tasks. Second, the memory and nesting behaviors were evaluated in the same groups of $\mathrm{Tg}$ mice before and after MgT treatment. Such experimental design should give more confidence in the observed effects of $\mathrm{MgT}$ in $\mathrm{Tg}$ mice.

To check whether the recovery of memory and social behavior in $\mathrm{Tg}$ mice was associated with restoring the synaptic density, we quantified synaptophysin labeled presynaptic terminals in aged WT mice and aged $\mathrm{Tg}$ mice with 1 month of MgT treatment (perfused at age of 24 month). Strikingly, in aged Tg mice with 1 month of MgT treatment, the presynaptic terminal density in hippocampal DG was restored to a level comparable to that of aged WT ( $\mathrm{p}=0.7$, Figure 7F, for ANOVA analysis see Table 2). These data suggest that elevation of brain magnesium reversed the behavioral and structural deficits even at the end-stage of the AD-like pathological progression in Tg mice.

Besides the progressive impairment in cognitive abilities, the lifespan of $\mathrm{Tg}$ mice was significantly lower than that of
WT. MgT treatment prevented the premature death of $\mathrm{Tg}$ mice (Figure 7G). This longevity with more normal cognitive function highlights the overall beneficial effects of $\mathrm{MgT}$ treatment on body health, at least in mice.

\section{Discussion}

In our previous study, we show that elevation of brain magnesium enhances learning and memory abilities of young and aging rats [18]. Here, we show that elevating brain magnesium was effective in preventing/reversing learning and memory deterioration in APPswe/PS1dE9 transgenic mice, a model of AD-like pathologies. Comparison of synaptic signaling pathways among WT, Tg, and $\mathrm{Tg}+\mathrm{MgT}$ mice reveals that failure in activating NMDAR signaling is among the major AD-like pathological progression in the APPswe/PS1dE9 mice. The recording studies from hippocampal slices illuminate how elevation of brain magnesium might exert its neuroprotective effects on NMDAR signaling. Unexpectedly, we found that elevation of brain magnesium could prevent dysfunctions in APP metabolism by stabilizing the expression of BACE1 in APPswe/PS1dE9 mice, which might also contribute to the prevention of memory deterioration by $\mathrm{MgT}$ treatment. The most striking finding in the current study is that elevation of brain magnesium was effective in restoring synapse density at the end-stage of AD-like pathological progression in APPswe/PS1dE9 mice, which might be responsible to the restoration of cognitive functions.

\section{How does elevation of brain magnesium protect NMDAR signaling in the APPswe/PS1dE9 transgenic mice?}

How dysfunctions of APP metabolism lead to synaptic dysfunctions/loss has been extensively studied [19]. The NMDAR signaling pathway is likely to be one of the primary mechanisms underlying memory deficits in the APPswe/PS1dE9 mice, as NMDARs play a pivotal role in memory processes [27]. A recent study shows that protection of NMDARs is sufficient to ameliorate the memory deficits in an animal model of AD [29]. In the current study, activation of the NMDAR signaling was dramatically impaired in APPswe/PS1dE9 mice. This deficit is likely to be caused by dysfunctions in $\mathrm{Ca}^{2+}$ homeostasis in these mice. Cytosolic $\mathrm{Ca}^{2+}$ level is hypothesized to be elevated during $\mathrm{AD}$ pathologies [30]. $A \beta$ can increase $\mathrm{Ca}^{2+}$ entry into the cell either by functioning as a $\mathrm{Ca}^{2+}$ channel or by activating plasma membrane $\mathrm{Ca}^{2+}$ channels [31,32], which might contribute to elevation of cytosolic $\mathrm{Ca}^{2+}$ levels under basal conditions in APPswe/PS1dE9 mice [33]. The increase in intracellular basal $\mathrm{Ca}^{2+}$ induces upregulation of calpain/calcineurin/Cdk5 neurodegenerative signaling [34]. These signaling molecules are known as the major downregulators of NMDARs for review see [35]. Hence, the downregulation of NMDARs by elevated $A \beta$, might be mediated 


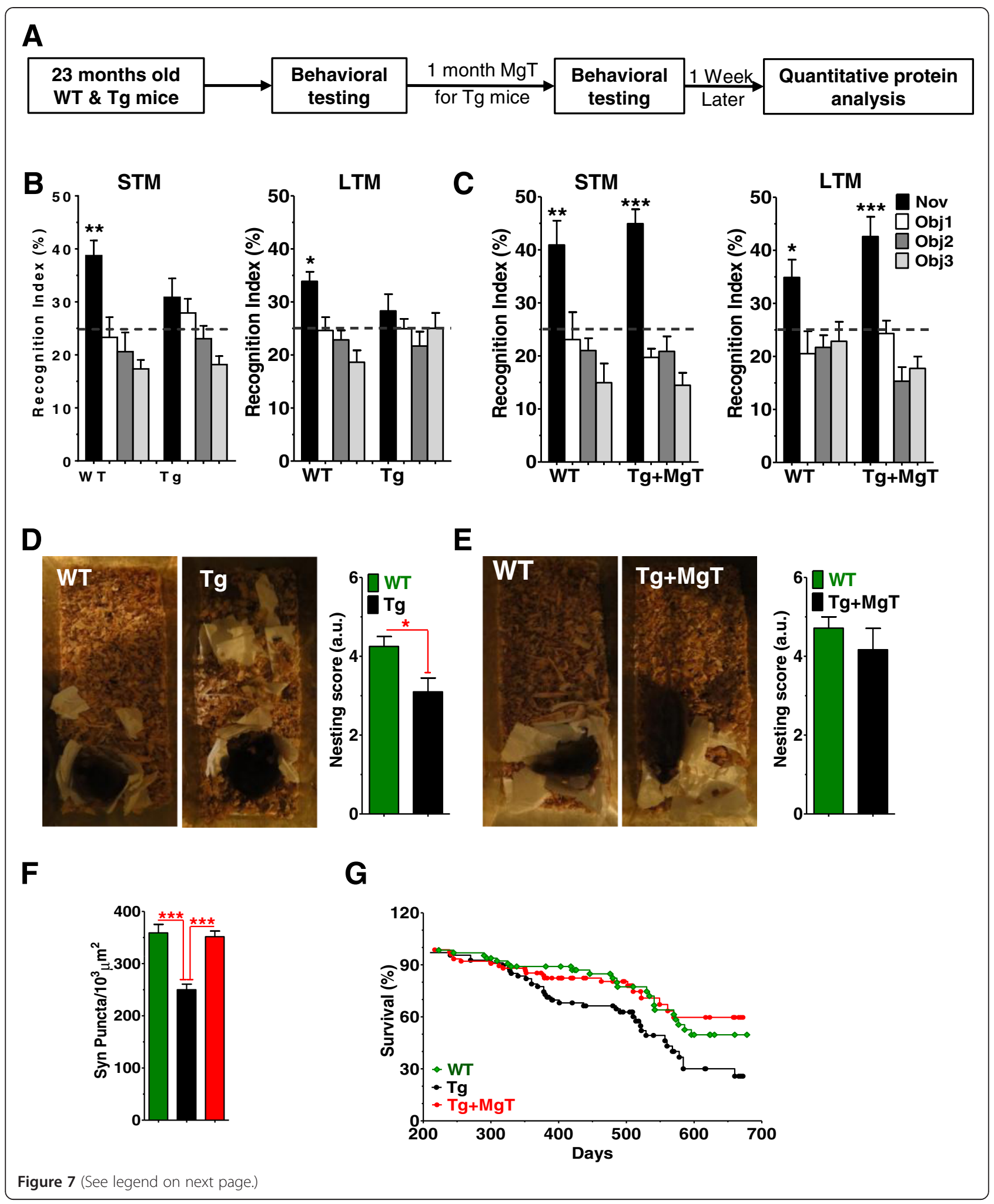


(See figure on previous page.)

Figure 7 Reversal by MgT treatment of behavioral and structural deficits in aged APPswe/PS1dE9 mice (Tg mice) and prevention of their premature death. (A) Experimental design to test whether MgT treatment can reverse behavioral deficits in aged Tg mice. (B) Recognition index of the novel object (Nov) and other familiar objects (Obj 1-3) during STM (left) and LTM (right) tests in the NORT task. WT ( $n=10$, ANOVA, STM: $p<0.0001 ;$ LTM: $p<0.0001)$ and untreated Tg $(n=8)$. (C) Same as $(\mathbf{B})$ and on the same mice but NORT tests were re-conducted after MgT treatment was given to Tg mice for 1 month. ANOVA revealed significant differences in WT $(n=8, \mathrm{STM}: p<0.001 ; \mathrm{LTM}: p<0.05)$ as well as in MgT-treated aged Tg mice ( $n=7$, STM: $p<0.0001$; LTM: $p<0.0001$ ). Dashed lines represent chance levels of performance (25\%). ANOVA was followed by Bonferroni's post hoc test. (D) Nest construction social behavior in WT $(n=10)$ and untreated Tg mice ( $n=10)$. (E) Same as (D) and on the same WT $(n=7)$ and $\mathrm{Tg}(n=6)$ mice, but after MgT treatment was given to Tg for 1 month. (F) Density of synaptophysin positive terminals (Syn Puncta). Data from untreated aged Tg mice (from Figure 2B) were inserted (black bars) to show the effects of the 1 month treatment. ANOVAs (Table 2) were followed by Bonferroni's post hoc test. Error bars show SEM. ${ }^{*} p<0.05,{ }^{* *} p<0.01,{ }^{* * *} p<0.001$. (G) Survival curves of WT $(n=65), \operatorname{Tg}(n=68)$ and Tg + MgT $(n=76)$ over 678 days of lifespan (MgT treatment started at 6 months of age). Log-rank Mantel-Cox test revealed significant difference between $\mathrm{Tg}$ mice and $\mathrm{WT}(p<0.05)$ as well as $\mathrm{Tg}+\mathrm{MgT}(p<0.01)$.

by the upregulation and/or overactivation of calpain and/ or calcineurin [28].

In MgT-treated APPswe/PS1dE9 mice the NMDAR signaling pathway was indifferent from WT mice. We hypothesize that $\mathrm{Mg}^{2+}$ might inhibit and/or downregulate calcineurin to prevent downregulation of NMDAR signaling (Figure 4F). In our previous studies, we demonstrated that elevation of $\left[\mathrm{Mg}^{2+}\right]_{\mathrm{o}}$ reduces $\left[\mathrm{Ca}^{2+}\right]_{\mathrm{i}}$, which was associated with NMDARs activation under resting-membrane potentials [17]. This reduction in $\left[\mathrm{Ca}^{2+}\right]_{\mathrm{i}}$ triggers homeostatic upregulation of NR2B-containing NMDARs in vitro [17] and in intact animals [18]. In the current study, we show that calcineurin is one of primary molecules mediating the effects of elevating $\left[\mathrm{Mg}^{2+}\right]_{0}$. Since both $\mathrm{A} \beta$ and $\left[\mathrm{Mg}^{2+}\right]_{0}$ regulate NMDARs by modulating the activity of calcineurin, we propose that the protective effects of $\left[\mathrm{Mg}^{2+}\right]_{\mathrm{o}}$ on NMDARs in high $\mathrm{A} \beta$ background might be largely mediated by preventing overactivation/overexpression of calcineurin. In support of the role of overactivation of calcineurin in $\mathrm{AD}$-like pathologies, inhibition of calcineurin alone ameliorates the AD-like pathologies in AD mouse model [36].

\section{How could elevation of brain magnesium lead to downregulation of BACE1?}

Intriguingly, elevation of brain magnesium not only protected NMDAR signaling, but also reduced the expression of BACE1, a critical enzyme that cleaves APP. Recent studies suggest that dysfunctions in APP cleavage by BACE1 might be the primary factor underlying the synapse loss and memory deficits in an AD mouse model [3] and the degeneration of cortical neurons in vitro [4]. Inhibition [3] or partial reduction of expression $[37,38]$ of BACE1 rescues synaptic/memory deficits in mouse models of AD. Therefore, the reductions in BACE1 expression by $\mathrm{MgT}$ treatment could contribute to the prevention of synapse loss and improvement of cognitive function in the APPswe/ PS1dE9 mice. In the current study, the exact molecular mechanisms underlying prevention of BACE1 overexpression by MgT treatment remain elusive.
Based on the above interpretations, we attributed the positive effects of MgT treatment on cognitive abilities in Tg mice to its protecting actions on the NMDAR signaling pathway and/or stabilizing of BACE1 expression. However, several studies reported increased incidence of epileptic seizures in AD patients [39] and in mouse models of AD [40]. Recently, it was shown that low doses of the antiepileptic drug, levetiracetam, normalize neuronal activity and reverse cognitive deficits in a mouse model of AD [41]. Acute infusions of high doses of $\mathrm{Mg}^{2+}$, which elevate blood $\mathrm{Mg}^{2+}$ concentration by $\sim 2.5-4$ folds, are effective in reducing seizures acutely in the clinical settings $[42,43]$. This seizure attenuation is due to direct blockage of presynaptic calcium channels by $\mathrm{Mg}^{2+}[44,45]$. Therefore, an alternative interpretation of the positive effects of MgT treatment is that elevation of brain magnesium increases calcium channels blockage, resulting in reductions in brain seizures. However, for such mechanism to become effective, the $\mathrm{Mg}^{2+}$ concentration in blood has to be elevated significantly. In the current study oral administration of MgT only elevates plasma magnesium by $\sim 0.1 \mathrm{mM}$ (Figure $1 \mathrm{G}$ ) and brain magnesium by $15 \%$ (Figure $1 F$ ). Since the gating of NMDARs is very sensitive to elevations of extracellular $\mathrm{Mg}^{2+}$ concentrations [17], the neuroprotective effects of MgT treatment are more likely to be mediated by its action on NMDARs.

\section{Magnesium concentration and synaptic function}

Our studies demonstrate that an increase in magnesium intake enhances memory in young rats, reverses memory decline in aged rats [18] and prevents memory deterioration a mouse model of AD (the current study). However, it is intriguing that following long-term magnesium supplementation, CSF $\mathrm{Mg}^{2+}$ concentration only increases by $15 \%$ [18] and total magnesium in brain increased by $30 \%$ (percentage of $\mathrm{Tg}$ mice, Figure 1F). Can small increases in $\left[\mathrm{Mg}^{2+}\right]_{\mathrm{CSF}}$ have major impact on synapse density? In a separate study, we found that increase extracellular $\mathrm{Mg}^{2+}$ by $15 \%$ leads to $~ 50 \%$ increase in synapse density in 
cultured hippocampal synapses (unpublished observations). These data suggest that hippocampal synapse density might be very sensitive to small changes in extracellular $\mathrm{Mg}^{2+}$ concentrations. Under normal physiological conditions, whole body magnesium is tightly regulated by kidney function. Daily fluctuation of plasma magnesium associated with food intake is less than $0.1 \mathrm{mM}$ above a baseline of $0.7 \mathrm{mM}$ [46]. Brain magnesium is supposed to be more stable as the blood-brain barrier isolates the brain from daily fluctuations in blood magnesium. Therefore, despite the high sensitivity of the synapses to $\mathrm{Mg}^{2+}$ concentration, synapse density is likely to be stable under physiological conditions. On the other hand, if brain magnesium is reduced under pathological conditions, it might have profound impact on synapse density and memory function. Interestingly, in the hippocampus of $\mathrm{AD}$ patients, the total magnesium level is reduced by $18 \%$ [20]. Therefore, restoration/elevation of brain magnesium in $\mathrm{AD}$ patients might be beneficial for ameliorating the cognitive deficits of $\mathrm{AD}$.

\section{Methods}

\section{Experimental animals}

Six hemizygous transgenic ( $\mathrm{Tg}$ ) male mice (APPswe/ PSEN1dE9)-85Dbo (referred to as 'Tg mice') and six noncarrier female mice were obtained and bred in Peking University's laboratory animal center according to protocol provided by the supplier (The Jackson Laboratories). In the breeding colony, we generated 1000 mice in total, which were genotyped routinely to identify the $\mathrm{Tg}$ mice. Overall, $\sim 250$ male wild type (WT) and $\sim 250$ male $\mathrm{Tg}$ mice we prepared and majority of them were used in the current study. Animals were housed individually in a controlled environment (temperature $21 \pm 1^{\circ} \mathrm{C}$, humidity $50 \pm$ $10 \%$ ) under inverted light cycle (light off 9:00 AM to 9:00 PM). Behavioral experiments were performed under red dim light. All experiments were performed on male mice except Western blot experiments in which female mice were used (WT: $\mathrm{n}=48$; Tg: $\mathrm{n}=48$ ). To conduct molecular, cellular and structural analysis, animals were sacrificed at ages of 15, 18, 23 or 24 months old (for details on each experiment see Results section). Experiments involving animals were approved by Tsinghua and Peking Universities Committees on Animal Care.

\section{Treatment with Magnesium-L-Threonate}

Magnesium-L-Threonate (MgT, Magceutics, Inc., CA, USA) treated $\mathrm{Tg}$ and/or WT mice received the $\mathrm{MgT}$ treatment via drinking water at a dose of $\sim 910 \mathrm{mg} / \mathrm{kg} /$ day $(\sim 75 \mathrm{mg} / \mathrm{kg} /$ day elemental magnesium). This dose was determined by scaling the minimum effective dose in rats, which we described before [18]. To monitor the dose of $\mathrm{MgT}(\mathrm{mg} / \mathrm{kg} /$ day), water intake and body weight were measured on daily basis $(8: 30 \mathrm{pm})$. The amount of MgT necessary to reach the target dose was calculated, based on the body weight, and dissolved in the daily drinking water ( $\sim 6 \mathrm{ml} /$ day/mouse) of individual animals. The MgT treatment was started when the mice were at the age of 6 months and lasted until animals were sacrificed, excluding the end-stage treatment experiments (Figure 7A-F) during which MgT treatment was given to Tg mice at age of 23 months for 1 month only. Untreated WT and Tg mice received tap water. All mice were maintained on standard food containing $0.15 \%$ elemental magnesium.

\section{Magnesium measurement in body tissues and fluids}

To determine the total magnesium content (ionized and non-ionized) in different body tissues, mice were transcardially perfused and then different body tissues; such as kidney, liver, muscles, fur, heart, and brain, were dissected. Total magnesium content in different tissues was measured using inductively coupled plasma optical emission spectroscopy (ICP-OES, Chemical Analysis Center, Tsinghua University). To determine the free $\mathrm{Mg}^{2+}$ concentration in the plasma and intracellular compartment of red blood cells, blood samples were collected from the orbital sinus, centrifuged and plasma was collected for measurement immediately. $\mathrm{Mg}^{2+}$ concentration in the plasma was measured using Calmagite chromometry as we described before [18]. The intracellular $\mathrm{Mg}^{2+}$ concentration in red blood cell (RBC, Figure $1 \mathrm{H}$ ) was determined by flow cytometry (Center for Biomedical Analysis, Tsinghua University). The fluorescent optical density (OD) was used as an indicator of the $\mathrm{Mg}^{2+}$ concentration in $\mathrm{RBC}$. The presented data represent the average of OD of 10000 RBCs for each mouse.

\section{Morris water maze (MWM)}

Spatial reference memory was assessed using a modified version of the Morris water maze [47]. The pool was a circular metal tank, $100 \mathrm{~cm}$ in diameter, $50 \mathrm{~cm}$ deep, filled to a height of $35 \mathrm{~cm}$ with water. Water temperature was maintained at $21 \pm 1^{\circ} \mathrm{C}$ degree. An acrylic platform $(10 \mathrm{~cm}$ in diameter) was placed inside the pool, its upper surface $1 \mathrm{~cm}$ below the surface of the water, so that a mouse inside the pool would be unable to locate it visually. The pool was set in a moderately lit, circular enclosure made with black curtains. Four cues with different shape and color were placed within the maze, and other four different cues were placed externally on the curtains. These cues remained unchanged throughout the testing period. The combination of proximal and distal cues was used based on pilot experiments during which we tested the sensitivity of WT mice to distal and proximal cues. Under our experimental conditions the optimal learning curve for naïve WT mice (declining from $\sim 60 \mathrm{~s}$ to $\sim<20 \mathrm{~s}$ over the time course of training) was obtained upon combining proximal and distal cues. Two protocols were used: First, 
at 7 months of age, mice received the visible platform training session for one day (day 0). This session was followed by hidden platform training session for five days with five trials per day $(60 \mathrm{~s}$ per trial, $1 \mathrm{~h}$ inter-trial interval). Each mouse was placed into the water by hand, so that it faced the wall of the pool, at one of four starting positions. The sequence of these positions was randomly selected. The platform was set in the middle of one quadrant, equidistant from the center and the edge of the pool. If the mouse found the platform, it was allowed to remain there for $30 \mathrm{~s}$ and was then returned to its home cage. If the mouse was unable to find the platform within $60 \mathrm{~s}$, it was guided to and placed on the platform for $30 \mathrm{~s}$, the trial was terminated, and the maximum score of $60 \mathrm{~s}$ was given. In each trial, the latency to locate the hidden platform was recorded using Noldus video tracking system (Ethovision). The test trial (the memory retention test) was carried out $24 \mathrm{~h}$ after the last trial of the training session. During the test trial, the platform was removed and each mouse was put into the pool for $60 \mathrm{~s}$. The total time spent in the target quadrant (where the platform had been located during the training trials) was measured using the same video system. Experiments and video analysis were performed by experimenters who were not aware of the genotype and the treatment of each mouse.

Second, at 15 months of age, we modified the water maze protocol to increase the task's difficulty. The tank-diameter was increased to $120 \mathrm{~cm}$ with $12 \mathrm{~cm}$ diameter platform under open-environment (curtains were removed) around the water maze. Mice were trained for 4 days ( 6 trials per day, $60 \mathrm{~s}$ per trial, $1 \mathrm{~h}$ inter-trial interval).

\section{Novel-object recognition task}

A modified version of the novel-object recognition test [48] was used to evaluate short-/long-term recognition memories. The apparatus consisted of a square arena $(50 \times 50 \times 20 \mathrm{~cm})$ made of polyvinyl chloride with white walls and floor. An overhead camera and a video recorder were used to monitor and record the animal's behavior for subsequent analysis. Two days before the experiment, all mice received two sessions of habituation to the arena and test room $10 \mathrm{~m}$ per session/day. At day 3 , each mouse was first placed in the center of the box, and exposed to four identical objects for $5 \mathrm{~m}$ (sample phase). Then the mouse was returned to its cage. For short-term memory, a $5 \mathrm{~m}$ retention interval was used, during which one of the objects was replaced by a new novel object. The objects were placed in the same locations as the previous ones. The mice were placed back in the box and exposed to the three familiar objects and to the novel object for further $5 \mathrm{~m}$ (test phase). During this phase, the mouse explored each of the four objects. The exploration of an object was defined as directing the nose to the object at a distance of $2 \mathrm{~cm}$ and/or touching it with the nose and forepaws. Turning around the object without direct exploration was not considered. The session was recorded on video, and the frequency of object exploration was subsequently measured by the experimenters who were blind to the treatment and genotype of each group. Recognition index was calculated as percentage ratio of time of each object over total exploration time. The box and objects were cleaned with $20 \%$ ethanol between trials to prevent the build-up of olfactory cues. For long-term memory same procedure was used but the retention interval was $24 \mathrm{~h}$ and completely different objects were used.

\section{Nest construction test}

Mice were individually housed in plastic cages with approximately $1 \mathrm{~cm}$ of woodchip bedding lining the floor. Two hours after the onset of the dark phase, individual cages were supplied with a $20 \mathrm{~cm} \times 20 \mathrm{~cm}$ piece of paper towel torn into approximately $5 \mathrm{~cm} \times 5 \mathrm{~cm}$ squared pieces. Cages were observed for the next $12 \mathrm{~h}$. Pictures were taken for documentation before the evaluation. Nest construction was scored along a system as followed: $1=$ no biting or tears on the paper, $2=$ mild biting and/or tears without gathering, 3 = moderate biting and/or tears on the paper with moderate gathering of pieces, $4=$ the majority of papers torn and gathered in a good manner, and $5=$ the vast majority of paper torn into approximately $1 \mathrm{~cm}$ pieces and grouped into a corner of the cage. Twenty-four hours after the first nest construction test, $\mathrm{MgT}$ treatment of the Tg mice started and lasted for 1 month, whereupon the second test was conducted. Mice were tested in counterbalanced groups of mixed genotypes. Nest construction was scored by experimenters who were unaware of the treatment and genotype of each group.

\section{Brains preparation for electron microscopy and staining of presynaptic puncta and amyloid plaques}

Mice (under home cage conditions) were anesthetized with chloral hydrate and perfused transcardially with physiological saline followed by $4 \%$ paraformaldehyde in $0.1 \mathrm{M}$ phosphate buffer ( $\mathrm{pH} 7.4)$. The left hemispheres were immersed in the same fixative overnight, embedded in paraffin, and were prepared for presynaptic puncta and amyloid plaques immunostaining. The right hemispheres were prepared for transmission electron microscopy.

\section{Transmission electron microscopic analysis}

The right hemisphere was sectioned (500 $\mu \mathrm{m}$ thick coronal) to expose hippocampus. After brief rinse in $0.1 \mathrm{M}$ sodium cacodylate buffer ( $\mathrm{SCB}, \mathrm{pH} 7.4$ ), samples were immersion-fixed overnight in $2.5 \%$ glutaraldehyde and $2 \%$ paraformaldehyde in $0.1 \mathrm{M} \mathrm{SCB}$ containing $1 \%$ tannic acid. After rinsing in SCB and postfixation for $1 \mathrm{~h}$ in $1 \%$ osmium tetroxide, $0.1 \mathrm{M} \mathrm{SCB}$, the hippocampal sections were dehydrated using a series of acetone dilutions 
and were flat-embedded in an Epon resin. Semithin sections $(500 \mathrm{~nm})$ stained with toluidine blue were used to locate and trim granule cell layer and molecular layer of dentate gyrus in the hippocampus. Ultrathin sections $(60 \mathrm{~nm})$ stained with uranyl acetate and lead citrate, were examined with a JEOL-1200EX transmission electron microscope (Japan Electric Optical Laboratory) operated at $80 \mathrm{kV}$. Two sets of images were randomly captured at magnifications of 12,000 and 30,000, respectively. Scale bars were taken from scans of original electron micrograph negatives. Quantitative analysis was conducted on the digital EM micrographs of the same magnification from the outer molecular layer of the hippocampus dentate gyrus from all mice. The measurement was performed by experimenters who were not aware of the genotyping/ treatment and was assisted by MetaMorph software (Molecular Devices). Synapses were identified on the micrographs by the presence of postsynaptic density (PSD) and at least two synaptic vesicles in the axon terminal in close proximity. For the analysis of the synaptic density, the sets of lower magnification micrographs were used (24-26 micrographs for each mouse).

\section{Estimation of density of presynaptic puncta}

Density of synaptophysin-/glutamic acid decarboxylase $65 \mathrm{kD}$ (GAD65)-immunoreactive presynaptic terminals were quantified as we previously described for synaptophysin positive puncta [18]. Coronal sections $(6 \mu \mathrm{m}$ thick) from the left hemisphere were deparaffinized in xylene and rehydrated using a descending ethanol series followed by epitope retrieval with citrate buffer. After blocking with $5 \%$ normal serum (from the host of the secondary antibody) in PBS with $0.1 \%$ Triton X-100, tissue sections were incubated overnight with the primary antibody (see Table 3 for detailed information on each antibody) in PBS with $3 \%$ serum at $4{ }^{\circ} \mathrm{C}$. After washing in $\mathrm{PBS}$, sections were incubated with $\mathrm{CF}^{488}$-conjugated (Biotium Inc., CA, USA) secondary antibody (Table 3). After washing with PBS, sections were coverslipped with anti-fade mounting medium (Vectashield). Slides were coded until the completion of data analysis. Stained brain sections were imaged with Olympus IX-70 confocal microscope with the $60 \times$; water lens $(\mathrm{N} / \mathrm{A}=1.2)$ at zoom $\times 3$, generating an image with $78.6 \times 78.6 \mu \mathrm{m}$ dimension. Serial z-sectioning was performed (thickness of $0.6 \mu \mathrm{m}$ ) and the best three $\mathrm{z}$-sections (with highest number of puncta) were collected and merged into a single image. Therefore, volume of brain tissue per image is $\sim 78.6 \times$ $78.6 \times 1.8 \mu^{3}$. The number of synapses in the DG and CA1 subregions was estimated from the obtained images using Image-Pro-Plus software (Media Cybernetics). Background levels were equalized and special filters to separate fluorescent puncta were applied. Settings, for each image, were adjusted to maximize the number of detected fluorescent puncta. Mean puncta number per $1000 \mu \mathrm{m}^{2}$ was used as an estimate of the presynaptic puncta density.

\section{Amyloid plaque immunostaining}

Plaque burden was assessed by immunohistochemistry on paraffin-embedded sections using monoclonal anti-A $\beta$ antibodies 4G8 and/or 6E10 (Signet), as described previously [22]. Prior to immunostaining, sections were deparaffinized in xylene and washed in 100\% ethanol, 95\% ethanol, $70 \%$ ethanol, and water. Endogenous peroxidase

Table 3 Primary and secondary antibodies

\begin{tabular}{|c|c|c|c|c|}
\hline Experiments & Primary antibodies & Host & Dilution & Source \\
\hline \multirow[t]{2}{*}{ Quantitative immunostaining } & Synaptophysin & Mouse & 1:500 & Millipore \\
\hline & GAD65 & Rabbit & 1:500 & Millipore \\
\hline \multirow[t]{9}{*}{ Western blot } & NR2B & Rabbit & $1: 6000$ & Santa Cruz \\
\hline & pCamkll (THr286) & Rabbit & $1: 1000$ & Cell Signaling \\
\hline & Camkll & Rabbit & $1: 1000$ & Cell Signaling \\
\hline & pCreb (Ser133) & Rabbit & $1: 50$ & Cell Signaling \\
\hline & Creb & Rabbit & $1: 1000$ & Cell Signaling \\
\hline & GAPDH & Rabbit & $1: 6000$ & Cell Signaling \\
\hline & BACE1 & Rabbit & 1:500 & Cell Signaling \\
\hline & $6 \mathrm{E} 10$ ( $\beta-\mathrm{CTF})$ & mouse & $1: 6000$ & Signet \\
\hline & hsAPP $\beta$ & Rabbit & $1: 50$ & $\mathrm{IBL}$ \\
\hline Experiments & \multicolumn{2}{|c|}{ Secondary antibodies } & Dilution & Source \\
\hline \multirow[t]{2}{*}{ Quantitative immunostaining } & \multicolumn{2}{|c|}{$\mathrm{CF}^{\mathrm{TM}} 488$ Conjugated Goat anti-Mouse $\lg \mathrm{G}(\mathrm{H}+\mathrm{L})$} & 1:200 & Biotium \\
\hline & \multicolumn{2}{|c|}{$\mathrm{CF}^{\mathrm{TM}} 488$ Conjugated Goat anti-Rabbit $\lg \mathrm{G}(\mathrm{H}+\mathrm{L})$} & $1: 200$ & Biotium \\
\hline \multirow[t]{2}{*}{ Western blot } & \multicolumn{2}{|c|}{ HRP-conjugated Goat anti-Rabbit $\lg G(\mathrm{H}+\mathrm{L})$} & 1:20000 & ZSGB-BIO \\
\hline & \multicolumn{2}{|c|}{ HRP-conjugated Goat anti-Mouse $\lg G(\mathrm{H}+\mathrm{L})$} & $1: 25000$ & CST \\
\hline
\end{tabular}


activities in sections were quenched by $10 \mathrm{~m}$ incubations in $3 \% \mathrm{H}_{2} \mathrm{O}_{2}$ in methanol followed by epitope retrieval with citrate buffer and $5 \mathrm{~m}$ incubation in $85 \%$ formic acid. After rinse in PBS, nonspecific epitopes were blocked with normal horse serum. Then sections were incubated with primary antibody 4G8 and/or 6E10 (1:500 dilution) in PBS with $3 \% \mathrm{BSA}$ and incubated over night at $4{ }^{\circ} \mathrm{C}$ in a humid chamber. Sections were then washed in PBS and incubated with biotinylated secondary antibodies and avidin-biotinperoxidase as described by the manufacturer (Vectastain Elite $\mathrm{ABC}$ Kit) and visualized with diaminobenzidine tetrachloride (DAB). Stained sections containing hippocampus were examined with a Leica DM IRB inverted research microscope, using $5 \times$ objective, and digital images were captured with a Retiga 2000R digital camera (Qcaputure). The areas covered by amyloid plaque in the hippocampal formation and frontal cortex were calculated using ImagePro Plus. The area of interest was manually outlined, and the percentage of area occupied by $A \beta$ plaque, in the hippocampus and frontal cortex, was calculated.

\section{$A \beta 42$ and $A \beta 40$ concentrations in the cerebrospinal fluid} To determine the concentration of A $\beta 42$ and 40 monomers in the cerebrospinal fluid, mice were anesthetized with chloral hydrate $(400 \mathrm{mg} / \mathrm{kg}$, i.p.) and then the CSF was manually obtained from the cisterna magna by the interruption of the atlanto-occipital membrane using a recording pipettes (diameter $0.5 \mu \mathrm{m})$. CSF samples $(8 \mu \mathrm{l} /$ mouse) were collected and stored at $-20^{\circ} \mathrm{C}$ until measurement was performed. The $\mathrm{A} \beta 42$ and $\mathrm{A} \beta 40$ monomers concentrations were determined using ELISA kit (human $\beta$ amyloid [1-40] and [1-42] kits, Wako, Osaka, Japan). The procedure was performed with complete adherence to the manufacturer's instructions.

\section{Environmental enrichment-based stimulation for Western blot analyses}

For quantitative Western blot experiments (Figures 3, 5C-E and 6), mice were exposed to environmental enrichment-based behavioral stimulation for $24 \mathrm{~h}$ before being sacrificed. Mice were housed individually in standard cages (300 $\mathrm{cm}^{2}$ floor space), the stimulus of enrichment was divided into two phases: grouping (for $21 \mathrm{~h}$ ) and physical-training (for $3 \mathrm{~h}$ ). During the grouping phase, mice were group-housed in a large cage (5-6 mice/cage, $70 \mathrm{~cm} * 60 \mathrm{~cm} * 30 \mathrm{~cm}$ ) without any running wheels or toys. During the physical-training phase the mice in the large cage were given running wheels, play tubes, and wood boxes.

\section{Western blot}

Frozen $\left(-80^{\circ} \mathrm{C}\right)$ hippocampal tissues were homogenized and equal amounts of proteins were resolved on polyacrylamide gel, then transferred to PVDF membranes
(Millipore). Membranes were blocked and then probed with primary antibodies against NR2B (H-50, sc-9057, from Santa Cruz Biotechnology), BACE1 (D10E5), CREB, pCREB, CaMKII, pCaMKII, GAPDH (all from Cell Signaling Technology), sAPP $\beta$ (IBL) or $\beta$-CTF (6E10, Signet, see Table 3) overnight at $4^{\circ} \mathrm{C}$. Membranes were then incubated with an HRP-conjugated secondary antibody (ZSGB-BIO or CST, see Table 3) at room temperature. Protein bands were detected by ECL detection reagent (RPN2232; GE Healthcare) and captured on an autoradiography film (Kodak). Integrated optical density was determined using Image-Pro Plus software 6.0 (Media Cybernetics). Standard curves were constructed to establish that we operated within the linear range of the detection method. Co-detection of GAPDH on the same membrane served as a loading control. Quantitative analysis was performed by experimenters blind to the treated and/or genotype group.

\section{In vivo and in vitro recording}

\section{Input-output relationship in CA1 synapses in vivo}

Mice were anesthetized with urethane ( $2 \mathrm{~g} / \mathrm{kg}$, i.p.). The animals were fixed in a stereotaxic apparatus (Narishige SN-2, Japan). Field postsynaptic potentials (fPSPs) were recorded from the stratum radiatum in CA1 following electrical stimulation of Schaffer collateral-commissural pathway. The optimal electrode placement was determined using electrophysiological criteria as described before [49]. The recording electrode was positioned at $2.3 \mathrm{~mm}$ posterior to bregma, $1.75 \mathrm{~mm}$ lateral to midline and the depth of recording electrode was about $1.6 \mathrm{~mm}$ from dura. The stimulating electrode was positioned $1.7 \mathrm{~mm}$ posterior to bregma and $1.6 \mathrm{~mm}$ lateral to midline and about $1.8 \mathrm{~mm}$ from dura. The positions of the recoding and stimulation electrodes were confirmed by trailing the electrodes in brain sections from representative animals. A single square pulse of voltage at low frequency $(0.066 \mathrm{~Hz}, 0.2 \mathrm{~ms}$ duration) was used to evoke fPSPs and the intensity of the test stimulus was adjusted to produce $\sim 50-55 \%$ of maximum response.

\section{Slice preparation for in vitro recordings}

Acute coronal slices of hippocampus $(400 \mu \mathrm{m}$ thick) were prepared from 4 weeks old male C57BL/6 mice as described before [50]. Briefly, slices were transferred and submerged in a recovery chamber containing oxygenated $\left(95 \% \mathrm{O}_{2}\right.$ and $\left.5 \% \mathrm{CO}_{2}\right)$ artificial cerebrospinal fluid (ACSF, mM): $125 \mathrm{NaCl}, 2.5 \mathrm{KCl}, 2 \mathrm{CaCl}_{2}, 1.2$ or 0.8 $\mathrm{MgCl}_{2}, 26 \mathrm{NaHCO}_{3}, 1.25 \mathrm{NaH}_{2} \mathrm{PO}_{4}, 25$ glucose. The extracellular magnesium concentration $\left(\left[\mathrm{Mg}^{2+}\right]_{\mathrm{o}}\right)$ varied according to the experimental conditions. Slices were incubated in ACSF containing either physiological extracellular magnesium concentration $\left(\left[\mathrm{Mg}^{2+}\right]_{\mathrm{o}}=0.8 \mathrm{mM}\right)$ or high $\left[\mathrm{Mg}^{2+}\right]_{\mathrm{o}}(1.2 \mathrm{mM})$, at $32^{\circ} \mathrm{C}$ for $1 \mathrm{~h}$ and then at 
room temperature for $3 \mathrm{~h}$ before recording. Irrespective of the pre-incubation conditions, the recording was performed under $1.2 \mathrm{mM}\left[\mathrm{Mg}^{2+}\right]_{\mathrm{o}}$ to avoid any potential acute effect of elevating $\left[\mathrm{Mg}^{2+}\right]_{\mathrm{o}}$.

\section{Amyloid- $\beta$ and FK506}

Application of Amyloid- $\beta$ and FK506 was done as described before [28]. Briefly, Amyloid- $\beta 42$ monomer (1 $\mu \mathrm{M}$, Amyloid $\beta$-Protein Fragment 1-42, sigma) and/ or FK506 (10 $\mu \mathrm{M}$, Sigma) were applied into the ACSF after the $3 \mathrm{~h}$ recovery period and for $1 \mathrm{~h}$ before recording started.

\section{Whole-cell recordings in vitro}

Experiments were performed in a recording chamber on the stage of a microscope (Eclipse FN1, Nikon) with infrared DIC optics (IR1000, DAGE-MTI) for visualizing wholecell patch-clamp recordings. EPSCs were recorded from CA1 pyramidal neurons, using an EPC-9 amplifier with Pulse v8.65 software (HEKA Elek., Lambrecht, Germany), while stimulating the Schaffer collateral-commissural pathway. A moderate constant amplitude stimulus, by Stimulus Isolator A365 (World Precision Instruments, Sarasota, FL USA) with bipolar tungsten stimulating electrode, was used to stimulate axonal fibers and a population of synapses. The extracellular solution also contained picrotoxin (100 $\mu \mathrm{M}$, Sigma) to block fast GABAergic inhibition. The recording pipettes (3-5 M $\Omega$ ) were filled with solution containing (mM): 130 Cs-gluconate, $4 \mathrm{NaCl}, 0.5 \mathrm{MgCl}_{2}, 5$ EGTA, 10 HEPES, 5 MgATP, $0.5 \mathrm{Na}_{3}$ GTP and 5 QX-314 (adjusted to pH 7.3 with $\mathrm{CsOH}$ and osm. 290-295 with double distilled water).

For $\mathrm{EPSC}_{\mathrm{NMDA}} / \mathrm{EPSC}_{\mathrm{AMPA}}$ experiments, after whole-cell patch-clamp, neurons were voltage clamped at $-70 \mathrm{mV}$ to record the $\mathrm{EPSC}_{\mathrm{AMPA}}$, and then were clamped at $+50 \mathrm{mV}$ to record the $\mathrm{EPSC}_{\mathrm{NMDA}}$ (with liquid junction potential correction). EPSCs were induced by repetitive stimulations at $0.1 \mathrm{~Hz}$. The peak amplitude of EPSC $_{\mathrm{AMPA}}$ was determined at the peak of the EPSCs recorded at $-70 \mathrm{mV}$, and the peak amplitude of $\mathrm{EPSC}_{\mathrm{NMDA}}$ was determined at $+50 \mathrm{mV}$ and $200 \mathrm{~ms}$ after stimulation. The $\mathrm{I}_{\mathrm{NMDA} / \mathrm{AMPA}}$ ratio was calculated from the recorded data of individual neurons.

\section{Statistics}

Learning curves in the water maze task were analyzed using Two-way ANOVA (treatment $\mathrm{x}$ trials) repeated measure. The water maze memory tests, NORT, magnesium contents in brain tissue, electron microscopy, fluorescent immunostaining and Western blot data were analyzed using One-way ANOVA. ANOVAs were followed by Bonferroni's post hoc test. All data involved comparing two groups were analyzed using two-tailed unpaired $t$-test. $P$ value less than 0.05 was considered statistically significant.

\section{Additional files}

Additional file 1: Figure S1. The raw data for Western Blot in Figure 5C-E.

Additional file 2: Figure S2. The raw data for Western Blot in Figure 6.

\section{Abbreviations}

MgT: Magnesium-L-Threonate; AD: Alzheimer's disease; NMDA: N-methyl-Daspartate; CREB: Cyclic AMP-Responsive Element-binding protein; BACE1: Beta-secretes 1; sAPP: Soluble beta Amyloid Precursor Protein; B-CTF: Beta- C-terminal fragment; NMDARs: N-methyl-D-aspartate receptors; APP: Amyloid Precursor Protein; AB: Amyloid beta; NAP: Neutrophil alkaline phosphatase; NGF: Nerve Growth Factor; BDNF: Brain-derived neurotropic factor; $\mathrm{Mg}^{2+}$ : Magnesium lon; Tg: Transgenic; WT: Wild type; ICP-OES: Inductively coupled plasma optical emission spectroscopy; RBC: Red blood cell; OD: Optical density; MWM: Morris water maze; SCB: Sodium CacodylateBuffer; PSD: Postsynaptic density; GAD65: Glutamic acid decarboxylase 65 kD; PBS: Phosphate buffered saline; BSA: Bovine serum albumin; DAB: Diaminobenzidine Tetrachloride; A 42 : Amyloid-beta 42; A 440 : Amyloid-beta 40; ELISA: Enzyme-linked immunosorbent assay; PVDF: Polyvinylidene Difluoride; NR2B: N-methyl D-aspartate receptor subtype 2B; pCREB: Phophorylated CAMP-responsive element bindingprotein; CaMK II: Calmodulin-dependent protein kinase II; GAPDH: Glyceraldehyde-3phosphate dehydrogenase; fPSPS: Field postsynaptic potentials; ACSF: fuid; EGTA: Ethylene glycol tetraacetic acid; HEPES: Ethanesulfonic acid; EPSC: Excitatory Postsynaptic Current; AMPA: a-amino-3-hydroxy-5-methyl-4isoxazole-propionic acid receptor; ANOVA: Analysis of variance; NORT: Novel object recognition test; DG: Dentate gyrus; GABA: Gamma amino butyric acid; fPSPs: Field postsynaptic potentials; CSF: Cerebrospinal fluid; PS1: Presenilin-1; STM: Short term memory; LTM: Long term memory; CNS: Central nervous system; SEM: Standard error of the mean; RI: Recognition index; IPP: Image pro plus; PSD: Postsynaptic density; OML: Outer molecular layer; NGF: Nerve growth factor; LTP: Long-term potentiation.

\section{Competing interests}

Guosong Liu declares that he is a co-founder of Magceutics, a company whose goal is to develop drugs to treat age-dependent memory decline and Alzheimer's disease. He also reports his United States patent application on "Magnesium-L-Threonate". All other authors report no financial interests or potential conflicts of interest related to the current study.

\section{Authors' contributions}

WL, NA, X-GL, and GL designed research; WL, JY, YL, Xiaojie Huang, YZ, Xian Huang, WX, CR, and DC performed research; WL, JY, and CR analyzed data; WL, $N A$, and GL wrote the paper. All authors read and approved the final manuscript.

\section{Acknowledgements}

This work was supported by the National Basic Research Program of China (973 program, Grant 2009CB941303, Grant 2011CB302201 to G.L., and Grant 2013 CB835102 to N.A.), and the National Natural Science Foundation of China (NSFC, Grant 81270048/H3101 to N.A. and Grant 30970957 to X-G. L.). We thank Jack L. Feldman for comments on the manuscript and Jiangyang Lu for technical support in electron microscopy.

\section{Author details}

${ }^{1}$ School of Medicine, Tsinghua University, Beijing, China. ${ }^{2}$ Neuroscience Research Institute, Health Science Center, Peking University, Beijing, China. ${ }^{3}$ Department of Physiology, Zhongshan School of Medicine, Sun Yat-sen University, Guangzhou, China.

Received: 30 June 2014 Accepted: 26 August 2014 Published online: 13 September 2014

\section{References}

1. Holtzman DM, Morris JC, Goate AM: Alzheimer's disease: the challenge of the second century. Sci Transl Med 2011, 3:77sr71. 
2. Selkoe DJ: Alzheimer's disease. Cold Spring Harb Perspect Biol 2011, 3(7):a004457.

3. Tamayev R, Matsuda S, Arancio O, D'Adamio L: beta- but not gammasecretase proteolysis of APP causes synaptic and memory deficits in a mouse model of dementia. EMBO Mol Med 2012, 4:171-179.

4. Nikolaev A, McLaughlin T, O'Leary DD, Tessier-Lavigne M: APP binds DR6 to trigger axon pruning and neuron death via distinct caspases. Nature 2009, 457:981-989.

5. Jack CR Jr, Knopman DS, Jagust WJ, Shaw LM, Aisen PS, Weiner MW, Petersen RC, Trojanowski JQ: Hypothetical model of dynamic biomarkers of the Alzheimer's pathological cascade. Lancet Neurol 2010, 9:119-128.

6. Terry RD, Masliah E, Salmon DP, Butters N, DeTeresa R, Hill R, Hansen LA, Katzman R: Physical basis of cognitive alterations in Alzheimer's disease: synapse loss is the major correlate of cognitive impairment. Ann Neurol 1991, 30:572-580.

7. Savva GM, Wharton SB, Ince PG, Forster G, Matthews FE, Brayne C: Age, neuropathology, and dementia. N Engl J Med 2009, 360:2302-2309.

8. Roe CM, Mintun MA, D'Angelo G, Xiong C, Grant EA, Morris JC: Alzheimer disease and cognitive reserve: variation of education effect with carbon 11-labeled Pittsburgh Compound B uptake. Arch Neurol 2008, 65:1467-1471.

9. Sperling RA, Jack CR Jr, Aisen PS: Testing the right target and right drug at the right stage. Sci Transl Med 2011, 3:111cm133.

10. Palop JJ, Mucke L: Amyloid-[beta]-induced neuronal dysfunction in Alzheimer's disease: from synapses toward neural networks. Nat Neurosci 2010, 13:812-818.

11. Greer PL, Greenberg ME: From synapse to nucleus: calcium-dependent gene transcription in the control of synapse development and function. Neuron 2008, 59:846-860.

12. Rockenstein E, Adame A, Mante M, Moessler H, Windisch M, Masliah E: The neuroprotective effects of Cerebrolysin in a transgenic model of Alzheimer's disease are associated with improved behavioral performance. J Neural Transm 2003, 110:1313-1327.

13. Matsuoka Y, Jouroukhin Y, Gray AJ, Ma L, Hirata-Fukae C, Li HF, Feng L, Lecanu L, Walker BR, Planel E, Arancio O, Gozes I, Aisen PS: A neuronal microtubule interacting agent, NAP, reduces tau pathology and enhances cognitive function in a mouse model of Alzheimer's disease. J Pharmacol Exp Ther 2008, 325(1):146-153.

14. De Rosa R, Garcia AA, Braschi C, Capsoni S, Maffei L, Berardi N, Cattaneo A: Intranasal administration of nerve growth factor (NGF) rescues recognition memory deficits in AD11 anti-NGF transgenic mice. Proc Natl Acad Sci U S A 2005, 102:3811-3816.

15. Nagahara AH, Merrill DA, Coppola G, Tsukada S, Schroeder BE, Shaked GM, Wang L, Blesch A, Kim A, Conner JM, Rockenstein E, Chao MV, Koo EH, Geschwind D, Masliah E, Chiba AA, Tuszynski MH: Neuroprotective effects of brain-derived neurotrophic factor in rodent and primate models of Alzheimer's disease. Nat Med 2009, 15:331-337.

16. Reger MA, Watson GS, Green PS, Wilkinson CW, Baker LD, Cholerton B, Fishel MA, Plymate SR, Breitner JC, DeGroodt W, Mehta P, Craft S: Intranasal insulin improves cognition and modulates beta-amyloid in early AD. Neurology 2008, 70:440-448.

17. Slutsky I, Sadeghpour S, Li B, Liu G: Enhancement of synaptic plasticity through chronically reduced $\mathrm{Ca}^{2+}$ flux during uncorrelated activity. Neuron 2004, 44:835-849.

18. Slutsky I, Abumaria N, Wu LJ, Huang C, Zhang L, Li B, Zhao X, Govindarajan A, Zhao MG, Zhuo M, Tonegawa S, Liu G: Enhancement of learning and memory by elevating brain magnesium. Neuron 2010, 65:165-177.

19. Selkoe DJ: Alzheimer's disease is a synaptic failure. Science 2002, 298:789-791.

20. Andrasi E, Pali N, Molnar Z, Kosel S: Brain aluminum, magnesium and phosphorus contents of control and Alzheimer-diseased patients. J Alzheimers Dis 2005, 7:273-284.

21. Barbagallo M, Belvedere M, Di Bella G, Dominguez LJ: Altered ionized magnesium levels in mild-to-moderate Alzheimer's disease. Magnes Res 2011, 24:S115-S121

22. Borchelt DR, Ratovitski T, van Lare J, Lee MK, Gonzales V, Jenkins NA Copeland NG, Price DL, Sisodia SS: Accelerated amyloid deposition in the brains of transgenic mice coexpressing mutant presenilin 1 and amyloid precursor proteins. Neuron 1997, 19:939-945.

23. Bernardo A, Harrison FE, McCord M, Zhao J, Bruchey A, Davies SS, Jackson Roberts L 2nd, Mathews PM, Matsuoka Y, Ariga T, Yu RK, Thompson R,
McDonald MP: Elimination of GD3 synthase improves memory and reduces amyloid-beta plaque load in transgenic mice.

Neurobiol Aging 2009, 30:1777-1791.

24. Ding Y, Qiao A, Wang Z, Goodwin JS, Lee ES, Block ML, Allsbrook M, McDonald MP, Fan GH: Retinoic acid attenuates beta-amyloid deposition and rescues memory deficits in an Alzheimer's disease transgenic mouse model. J Neurosci 2008, 28:11622-11634.

25. Reiserer RS, Harrison FE, Syverud DC, McDonald MP: Impaired spatial learning in the APPSwe + PSEN1DeltaE9 bigenic mouse model of Alzheimer's disease. Genes Brain Behav 2007, 6:54-65.

26. Reagan-Shaw S, Nihal M, Ahmad N: Dose translation from animal to human studies revisited. Faseb J 2008, 22:659-661.

27. Martin SJ, Grimwood PD, Morris RG: Synaptic plasticity and memory: an evaluation of the hypothesis. Annu Rev Neurosci 2000, 23:649-711.

28. Snyder EM, Nong Y, Almeida CG, Paul S, Moran T, Choi EY, Nairn AC, Salter MW, Lombroso PJ, Gouras GK, Greengard P: Regulation of NMDA receptor trafficking by amyloid-[beta]. Nat Neurosci 2005, 8:1051-1058.

29. Cisse M, Halabisky B, Harris J, Devidze N, Dubal DB, Sun B, Orr A, Lotz G, Kim DH, Hamto P, Ho K, Yu GQ, Mucke L: Reversing EphB2 depletion rescues cognitive functions in Alzheimer model. Nature 2011, 469:47-52.

30. Bezprozvanny I, Mattson MP: Neuronal calcium mishandling and the pathogenesis of Alzheimer's disease. Trends Neurosci 2008, 31:454-463.

31. Jang H, Arce FT, Ramachandran S, Capone R, Azimova R, Kagan BL, Nussinov R, Lal R: Truncated \{beta\}-amyloid peptide channels provide an alternative mechanism for Alzheimer's Disease and Down syndrome. Proc Natl Acad Sci U S A 2010, 107(14):6538-6543.

32. Alberdi E, Sanchez-Gomez MV, Cavaliere F, Perez-Samartin A, Zugaza JL, Trullas R, Domercq M, Matute C: Amyloid beta oligomers induce $\mathrm{Ca}^{2+}$ dysregulation and neuronal death through activation of ionotropic glutamate receptors. Cell Calcium 2010, 47:264-272.

33. Kuchibhotla KV, Goldman ST, Lattarulo CR, Wu HY, Hyman BT, Bacskai BJ: Abeta plaques lead to aberrant regulation of calcium homeostasis in vivo resulting in structural and functional disruption of neuronal networks. Neuron 2008, 59:214-225.

34. Shi J, Townsend M, Constantine-Paton M: Activity-dependent induction of tonic calcineurin activity mediates a rapid developmental downregulation of NMDA receptor currents. Neuron 2000, 28:103-114.

35. Lau CG, Zukin RS: NMDA receptor trafficking in synaptic plasticity and neuropsychiatric disorders. Nat Rev Neurosci 2007, 8:413-426.

36. Dineley KT, Hogan D, Zhang WR, Taglialatela G: Acute inhibition of calcineurin restores associative learning and memory in Tg2576 APP transgenic mice. Neurobiol Learn Mem 2007, 88:217-224.

37. McConlogue L, Buttini M, Anderson JP, Brigham EF, Chen KS, Freedman SB, Games D, Johnson-Wood K, Lee M, Zeller M, Liu W, Motter R, Sinha S: Partial reduction of BACE1 has dramatic effects on Alzheimer plaque and synaptic pathology in APP Transgenic Mice. J Biol Chem 2007, 282:26326-26334.

38. Singer O, Marr RA, Rockenstein E, Crews L, Coufal NG, Gage FH, Verma IM, Masliah E: Targeting BACE1 with siRNAs ameliorates Alzheimer disease neuropathology in a transgenic model. Nat Neurosci 2005, 8:1343-1349.

39. Palop JJ, Mucke L: Epilepsy and cognitive impairments in Alzheimer disease. Arch Neurol 2009, 66:435-440.

40. Palop JJ, Chin J, Roberson ED, Wang J, Thwin MT, Bien-Ly N, Yoo J, Ho KO, Yu GQ, Kreitzer A, Finkbeiner S, Noebels JL, Mucke L: Aberrant excitatory neuronal activity and compensatory remodeling of inhibitory hippocampal circuits in mouse models of Alzheimer's disease. Neuron 2007, 55:697-711.

41. Sanchez PE, Zhu L, Verret L, Vossel KA, Orr AG, Cirrito JR, Devidze N, Ho K, Yu GQ, Palop JJ, Mucke L: Levetiracetam suppresses neuronal network dysfunction and reverses synaptic and cognitive deficits in an Alzheimer's disease model. Proc Natl Acad Sci U S A 2012, 109:E2895-E2903.

42. Altman D, Carroli G, Duley L, Farrell B, Moodley J, Neilson J, Smith D: Do women with pre-eclampsia, and their babies, benefit from magnesium sulphate? The Magpie Trial: a randomised placebo-controlled trial. Lancet 2002, 359:1877-1890.

43. Lu JF, Nightingale $\mathrm{CH}$ : Magnesium sulfate in eclampsia and pre-eclampsia: pharmacokinetic principles. Clin Pharmacokinet 2000, 38:305-314.

44. Hubbard Jl, Jones SF, Landau EM: On the mechanism by which calcium and magnesium affect the spontaneous release of transmitter from mammalian motor nerve terminals. J Physiol 1968, 194:355-380.

45. Hubbard Jl, Jones SF, Landau EM: On the mechanism by which calcium and magnesium affect the release of transmitter by nerve impulses. J Physiol 1968, 196:75-86. 
46. Witkowski M, Hubert J, Mazur A: Methods of assessment of magnesium status in humans: a systematic review. Magnes Res 2011, 24:163-180.

47. Morris RG, Garrud P, Rawlins JN, O'Keefe J: Place navigation impaired in rats with hippocampal lesions. Nature 1982, 297:681-683.

48. Ennaceur A, Delacour J: A new one-trial test for neurobiological studies of memory in rats. 1: Behavioral data. Behav Brain Res 1988, 31:47-59.

49. Leung LW: Orthodromic activation of hippocampal CA1 region of the rat. Brain Res 1979, 176:49-63.

50. Wei F, Qiu CS, Kim SJ, Muglia L, Maas JW, Pineda W, Xu HM, Chen ZF, Storm DR, Muglia LI, Zhuo M: Genetic elimination of behavioral sensitization in mice lacking calmodulin-stimulated adenylyl cyclases. Neuron 2002, 36:713-726.

doi:10.1186/s13041-014-0065-y

Cite this article as: Li et al:: Elevation of brain magnesium prevents synaptic loss and reverses cognitive deficits in Alzheimer's disease mouse model. Molecular Brain 2014 7:65.

\section{Submit your next manuscript to BioMed Central and take full advantage of:}

- Convenient online submission

- Thorough peer review

- No space constraints or color figure charges

- Immediate publication on acceptance

- Inclusion in PubMed, CAS, Scopus and Google Scholar

- Research which is freely available for redistribution 